\title{
DEVELOPMENT OF TAMOXIFEN CITRATE PELLETS BY HOT-MELT EXTRUSION FOR IMMEDIATE RELEASE: STUDY OF EFFECT OF VARIABLES
}

\author{
VISHAL YADAV, S. SATHESH KUMAR* \\ *Department of Pharmaceutics, School of Pharmaceutical Sciences, Vels Institute of Science, Technology and Advanced Studies (VISTAS), \\ Pallavaram, Chennai 600117, India \\ Email: sathesh2000@gmail.com
}

Received: 04 May 2019, Revised and Accepted: 04 Jul 2019

ABSTRACT

Objective: Objective of the study was to develop tamoxifen citrate immediate release pellets by hot-melt extrusion (HME) and to study the effect of various formulation and process variables.

Methods: Pellets were prepared by HME technique. Effect of various parameters such as the concentration of ethylcellulose, PEG 6000, croscarmellose sodium, and spheronization speed were studied by using Central Composite Design. Pellets were evaluated for theoretical yield (\%), mean pellet size $(\mathrm{mm})$, sphericity (pellips), friability (\%), porosity (\%), mechanical crushing force (n), and dissolution efficiency. Optimized formulation was studied for compatibility study using IR, DSC, and XRD, SEM, In vitro drug release. In vitro Cell Cytotoxicity and Viability Assay were carried out using MCF-7 (human breast cancer cells) by MTT assay.

Results: Results showed that a variable such as the amount of Methyl Cellulose, PEG 6000 and Spheronization speed showed positive correlation and amount of Croscarmellose sodium showed a negative correlation with dependent variables. Optimized formulation showed Korsmeyer Peppas model as a mechanism of drug release. Value of $\mathrm{n}$ was found to be in between $0.77+0.04$, which reveals that, release mechanism of the drug as non-Fickian transport $(0.45<\mathrm{n}<0.89)$. MTT results of MCF-7 cells showed that optimized immediate release pellets have maximum cytotoxicity at $80 \mu \mathrm{g} / \mathrm{ml}$.

Conclusion: Study concluded that HME method and materials i.e. PEG 6000 and methylcellulose can effectively use to get immediate release of tamoxifen citrate so as to increase dissolution rate and cytotoxic effect.

Keywords: Tamoxifen citrate, Pellets, Hot-melt extrusion, Immediate release, Central composite design

(c) 2019 The Authors. Published by Innovare Academic Sciences Pvt Ltd. This is an open-access article under the CC BY license (http://creativecommons.org/licenses/by/4.0/) DOI: http://dx.doi.org/10.22159/ijap.2019v11i5.33933

\section{INTRODUCTION}

One of the greatest difficulties confronted today by the pharmaceutical industries lies in empowering the conveyance of inadequately watersoluble drug. Solubility is a basic physicochemical property of the drug, as it legitimately identifies with a bioavailability of the atom inside in the body. Tamoxifen citrate (TMC) is BCS class II drug commercially converted to salt form as citrate to increase so as to increase its aqueous solubility and efficacy. Although it is in the salt form its solubility in water is limited as it has a higher melting point $\left(146^{\circ} \mathrm{C}\right)$ which inhibits its dissolution [1].

Hot-Melt Extrusion (HME) is an effective technique for delivering solid molecular dispersions with significant advantages over solvent-based technique such as spray drying and co-precipitation. HME is successfully used to develop sustained, modified, and targeted drug delivery. HME technique is presently used in pharmaceutical industries for various applications because of its numerous advantages over traditional methods [2].

TMC is a poorly water-soluble drug having pKa 8 and equilibrium solubility in water at $37^{\circ} \mathrm{C}$ is $0.5 \mathrm{mg} / \mathrm{ml}$. Hence dissolution from its dosage forms is also low and is a limiting step in the absorption process. It was reported that the dissolution of TMC can be enhanced to some level by preparing micro-emulsions and solid lipid nanoparticles [3-6]. Enhanced dissolution of TMC using watersoluble polymer has not yet reported in the literature. Thus, we focused on the present study on enhancing the dissolution power of drug by Hot-Melt Extrusion (HME) technique. The objective of present work was to study the effect of different variables such as the concentration of Methyl Cellulose, PEG 6000, Croscarmellose Sodium and Spheronization Speed on dissolution efficiency.

\section{MATERIALS AND METHODS}

\section{Materials}

Tamoxifen Citrate was received as a gift sample from USV Private Limited Govandi, Mumbai, India. Polyethylene glycol 6000 and
Methylcellulose were generously gifted by Merck Specialities Pvt. Ltd, Mumbai., India. Citric acid and Croscarmellose sodium were purchased from Qualigens Fine Chemicals and Spectrum Chemical Mfg. Corp. Mumbai, India respectively.

\section{Methods}

Preparations of pellets by hot-melt extrusion technique

Central Composite Design (CCD) with quadratic and 2FI as design model was used to design experiment. Formulation batches with different variable are shown in table 1 . The required quantities of drug and excipients i.e. PEG 6000, Methylcellulose, anhydrous citric acid (20\%), Avicel PH 101, Croscarmellose sodium were passed individually through 40 \# ASTM stainless steel sieve. Drug, excipients and each of the polymers was uniformly mixed in a lab-scale planetary mixer (Umang Pharmatech Pvt. Ltd.) for $10 \mathrm{~min}$. Then blend was transferred to $16 \mathrm{~mm}$ co-rotating twin screw melt extruder and operated at temperatures between 70 and $140{ }^{\circ} \mathrm{C}$, depending on the processability of the formulation. The screw speed was set to $20 \mathrm{rpm}$, motor load to 0.700 drive amperes, and the pressure didn't exceed 200 PSI. Screen for extrusion used was of $0.5 \mathrm{~mm}$ perforations diameter and $1.5 \mathrm{~mm}$ thickness. Extrudates were converted to spherical pellets using spheronizer (Cronimach, India) operated at $700 \mathrm{rpm}$. The obtained extrude product was further spheronised to obtain spherical pellets. Formed pellets were again blended with Magnesium stearate for $10 \mathrm{~min}[7,8]$.

\section{Characterization of pellets prepared by HME}

\section{Mean pellet size}

$200 \mathrm{~g}$ of sample was used for mean pellet size analysis. The pellets were sieved through sieves having aperture sizes from 250 to 2800 $\mathrm{mm}$ on mechanical sieve shaker (EMS-8, Electrolab, India) for 10 min. Geometric mean pellet size and size distribution were calculated using the equation given by Heng et al. [7] 


\section{Usable yield (\% theoretical)}

The usable yield of the pellets was determined by sieve analysis, using a sieve shaker (EMS-8, Electrolab, India) equipped with (600$2360 \mu \mathrm{m}$ ) sieves for $5 \mathrm{~min}$. at an amplitude of $2 \mathrm{~mm}$. This size fraction was used as a percent of total pellet weight $[8,9]$.

$$
\% \text { Yield }=\frac{\text { Weight of pellet }}{\text { Weight of Polymer }+ \text { Weight of Drug }} \times 100
$$

\section{Sphericity and shape analysis}

It is determined using an image analysis system. Photomicrographs of pellets were taken with a digital camera linked with a stereomicroscope system a stereomicroscope Leica S4E (Germany). Around 50 pellets were analyzed from every batch. The shape of each individual pellet was characterized as pellips $[8,10,11]$.

$$
\text { Pellips }=\frac{P}{\pi x d m a x}
$$

Where,

$\mathrm{P}$ is the perimeter and dmax is the maximum diameter of the pellet, calculated directly by using image analysis software.

\section{Abrasion resistance (friability)}

The friability of the pellets (\#14/22 fraction) was determined. Weighed amount pellets were subjected to test along with 24 steel balls (diameter about $2 \mathrm{~mm}$ ) in a Roche friabilator for 100 revolutions at $25 \mathrm{rpm}$ and then sieved through a \#22 sieve. The percent weight loss was then calculated [8].

\section{Porosity}

Pellet porosity is of great interest since more porous dosage forms usually exhibit faster drug release rates. Porous systems have more channels for water to enter and to dissolve the drug [12-14]. The effective porosity describes the space occupied by air inside a dosage form prior to the dissolution of the drug. Pellet porosity was calculated using the following equation, for percent effective porosity $[12,13]$

$$
\% \varepsilon=[(\rho \mathrm{t}-\rho \mathrm{b}) / \rho \mathrm{b}] \times 100
$$

Where,

$\varepsilon=$ effective porosity, $\rho \mathrm{t}=$ true density and $\rho \mathrm{b}=$ bulk density.

\section{Mechanical crushing force}

Tablet strength tester (EH 01, Electrolab, India) was used to measure mechanical crushing force. 20 pellets from the modal size fraction of each formulation were evaluated for their diametral crushing force $[15,16]$

\section{Densities}

The bulk density was determined using the graduated glass cylinder. The tapped density was determined using a tapped density test apparatus (USP, 2007).

\section{Flow property and compressibility studies}

Flowability of the pellets was assessed by determining the Carr's index (compressibility index), Hausner's ratio and angle of repose (Powder Flow 1174) [7, 8]

\section{Drug content}

The tamoxifen citrate pellets were assayed as per US pharmacopoeial method, using HPLC [1]

\section{In vitro drug release}

The USP basket apparatus type I was used for all the in vitro dissolution studies. $900 \mathrm{ml}$ of $0.02 \mathrm{~N} \mathrm{HCl}$ was used as dissolution media, at $100 \mathrm{rpm}$ and $37 \pm 0.5^{\circ} \mathrm{C} .5 \mathrm{ml}$ of the samples were taken at a suitable time interval $(5,10,20,30,40,50,60$, min.) and filtered through a $0.45 \mathrm{~mm}$ Millipore filter. Samples were assayed by the HPLC method $[17,18]$.

\section{Compatibility study}

Drug-excipient compatibility study was carried out using FTIR, DSC, and XRD.

\section{Scanning electron microscopy (SEM)}

Morphological examination of the surface was carried out using an SEM. SEM of pellets was obtained using JEOL JSM 6100 (JEOL, Japan).

\section{Stability studies}

The immediate-release pellets were subjected to stability studies. Pellets were filled into an empty hard gelatin capsule and were stored in tightly closed HDPE containers and in the aluminum pack. The stability studies were carried out at $40{ }^{\circ} \mathrm{C} \pm 2{ }^{\circ} \mathrm{C} / 75 \% \mathrm{RH} \pm 5 \%$ as per ICH guidelines (ICH, 2003). The stability samples were analyzed at 1,2, 3 and 6 mo for assay and dissolution studies. F2 value was calculated using following equation to ensure the equivalence with initial samples [19].

$$
f 2=50 \log \left\{\left[1+1 / n \sum_{t=1}^{n}(R t-T t)\right]^{0.5} \times 100\right\}
$$

\section{In vitro cell cytotoxicity and viability assay}

\section{Cell culture experiment}

Cell line study was performed on (MCF-7) (human breast cancer cells) procured from National Center for Cell Science (NCCS), Pune, India. Cells were maintained in T-25 tissue culture grade flask and cells were cultured in Dulbecco's Modified Eagle Medium (DMEM) supplemented with $10 \%$ heat-inactivated fetal bovine serum (FBS), 2 mmol glutamine, $1 \%$ penicillin and streptomycin mix to discourage growth of microorganisms and maintained in humidified atmosphere at $5 \% \mathrm{CO}_{2}$ at $37 \pm 0.5{ }^{\circ} \mathrm{C}$ grown to $80 \%$ confluence in tissue culture humidified environment [28].

\section{Methyl thiazole tetrazolium (MTT) assay}

Day 1: $1 \times 10^{5} \mathrm{cells} / \mathrm{ml}$ was added in 96 well plates (cell count was taken on Neubauer's chamber). Then the plate was incubated at $37^{\circ} \mathrm{C}$ in a $\mathrm{CO}_{2}$ incubator for $24 \mathrm{~h}$.

Day 2: After $24 \mathrm{~h}$ incubation plate was observed under an inverted microscope. A sterile test sample of scaffolds was added in triplicate. $100 \mu \mathrm{l}$ extract media of scaffold sample was added in triplicate. After this plate was incubated at $37^{\circ} \mathrm{C}$ in a $\mathrm{CO}_{2}$ incubator for $24 \mathrm{~h}$.

Day 3: After $24 \mathrm{~h}$ incubation plate was observed under an inverted microscope. A test sample of scaffolds was removed and $100 \mu \mathrm{l}$ fresh DMEM medium was added. Then $10 \mu \mathrm{l}$ of $5 \mathrm{mg} / \mathrm{ml}$ MTT reagent was added in each well. Plate wrapped in aluminum foil was incubated for $4 \mathrm{~h}$ in a $\mathrm{CO}_{2}$ incubator. After $4 \mathrm{~h}$ incubation plate was removed and observed under an inverted microscope and photographs were taken. After $1 \mathrm{hr}$ absorbance was measured at $492 \mathrm{~nm}$ on 96 well Plate reader. Cell viability (\%) and cytotoxicity (\%) was calculated using the following formula:

$$
\text { Cell Viability }(\%)=[\mathrm{A}] \text { test } /[\mathrm{A}] \text { control } \times 100
$$

Where, $[A]$ test is the absorbance of the test sample and $[\mathrm{A}]$ control is the absorbance of control samples.

$$
\text { Cytotoxicity }(\%)=100-\text { Cell viability (\%) }
$$

Concentration Tested: $1,10,20,40,80$ and $100 \mu \mathrm{g} / \mathrm{ml}$ for the sample.

\section{RESULTS AND DISCUSSION}

Formulation and characterization of immediate-release pellets

Formulation batches and results of characterization are summarized in table 1.

\section{Statistical analysis of the data and validation of the optimization model}

The design expert version 7.0 software (Minnesota, USA) was used in the current study for the generation and evaluation of the 
statistical experimental design. The independent variables concentration of methylcellulose (\%), PEG 6000, Croscarmellose Sodium (\%) and Spheronization Speed (rpm) of pellet obtained by using melt extrusion and spheronization technique against dependent variables i.e. Theoretical Yield (\%), Mean Pellet Size $(\mathrm{mm})$, Sphericity (pellips), Friability (\%), Porosity (\%), Mechanical Crushing Force(N) and dissolution efficiency (DE) was studied (table 2).

Table 1: Formulation and characterization of pellets

\begin{tabular}{|c|c|c|c|c|c|c|c|c|c|c|c|}
\hline \multirow{2}{*}{$\begin{array}{l}\text { Formula } \\
\text { tion }\end{array}$} & \multicolumn{4}{|c|}{ Variables } & \multicolumn{7}{|c|}{ Responses } \\
\hline & $\begin{array}{l}\text { Methyl } \\
\text { cellulo } \\
\text { se }(\%)\end{array}$ & $\begin{array}{l}\text { Poly } \\
\text { ethenyl } \\
\text { glycol } \\
6000 \\
\end{array}$ & $\begin{array}{l}\text { Spheroniza } \\
\text { tion speed } \\
\text { (rpm) }\end{array}$ & $\begin{array}{l}\text { Croscarm } \\
\text { ellose } \\
\text { sodium } \\
(\%)\end{array}$ & $\begin{array}{l}\text { Theoret } \\
\text { ical } \\
\text { yield } \\
(\%)^{*}\end{array}$ & $\begin{array}{l}\text { Mean } \\
\text { pellet } \\
\text { size } \\
(\mathrm{mm})^{*}\end{array}$ & $\begin{array}{l}\text { Spheri } \\
\text { city } \\
\text { (pellip } \\
\text { s) }\end{array}$ & $\begin{array}{l}\text { Friabilit } \\
\mathbf{y}(\%)^{*}\end{array}$ & $\begin{array}{l}\text { Poro } \\
\text { sity } \\
(\%)^{*}\end{array}$ & $\begin{array}{l}\text { Mechanic } \\
\text { al } \\
\text { Crushing } \\
\text { Force(N)* }\end{array}$ & $\begin{array}{l}\text { Dissolu } \\
\text { tion } \\
\text { efficien } \\
\text { cy }^{*}\end{array}$ \\
\hline F1 & 10 & 15 & 1100 & 2 & $62 \pm 0.92$ & $\begin{array}{l}745 \pm 22 . \\
2\end{array}$ & $\begin{array}{l}1.472 \pm \\
0.02\end{array}$ & $\begin{array}{l}0.995 \pm 0 \\
03\end{array}$ & $\begin{array}{l}2.47 \pm \\
0.05\end{array}$ & $3.4 \pm 0.05$ & $\begin{array}{l}74.55 \pm 3 \\
.50\end{array}$ \\
\hline $\mathrm{F} 2$ & 10 & 15 & 1100 & 4 & $59 \pm 0.66$ & $\begin{array}{l}864 \pm 17 \\
8\end{array}$ & $\begin{array}{l}1.328 \pm \\
0.08\end{array}$ & $\begin{array}{l}0.478 \pm 0 . \\
02\end{array}$ & $\begin{array}{l}5.21 \pm \\
0.08\end{array}$ & $4.02 \pm 0.06$ & $\begin{array}{l}74.00 \pm 4 \\
.80\end{array}$ \\
\hline F3 & 5 & 20 & 700 & 3 & $74 \pm 0.79$ & $\begin{array}{l}627 \pm 23 \\
8\end{array}$ & $\begin{array}{l}1.987 \pm \\
0.06\end{array}$ & $\begin{array}{l}0.62 \pm 0.0 \\
5\end{array}$ & $\begin{array}{l}4.21 \pm \\
0.07\end{array}$ & $2.54 \pm 0.08$ & $\begin{array}{l}76.13 \pm 4 \\
.63\end{array}$ \\
\hline $\mathrm{F} 4$ & 10 & 15 & 1100 & 2 & $52 \pm 0.32$ & $\begin{array}{l}1374 \pm 3 \\
6.9\end{array}$ & $\begin{array}{l}1.087 \pm \\
0.04\end{array}$ & $\begin{array}{l}0.427 \pm 0 \\
07\end{array}$ & $\begin{array}{l}3.02 \pm \\
0.09\end{array}$ & $4.02 \pm 0.09$ & $\begin{array}{l}78.00 \pm 5 \\
.74\end{array}$ \\
\hline F5 & 10 & 15 & 1100 & 2 & $58 \pm 0.89$ & $\begin{array}{l}1427 \pm 4 \\
0.8\end{array}$ & $\begin{array}{l}1.687 \pm \\
0.03\end{array}$ & $\begin{array}{l}1.054 \pm 0 . \\
09\end{array}$ & $\begin{array}{l}2.98 \pm \\
0.13\end{array}$ & $3.22 \pm 0.10$ & $\begin{array}{l}78.00 \pm 5 \\
.63\end{array}$ \\
\hline F6 & 5 & 20 & 1500 & 1 & $32 \pm 0.74$ & $\begin{array}{l}741 \pm 54 \\
3\end{array}$ & $\begin{array}{l}0.998 \pm \\
0.05\end{array}$ & $\begin{array}{l}0.21 \pm 0.0 \\
1\end{array}$ & $\begin{array}{l}1.04 \pm \\
0.08\end{array}$ & $1.05 \pm 0.05$ & $\begin{array}{l}82.44 \pm 6 \\
.32\end{array}$ \\
\hline F7 & 10 & 15 & 1100 & 2 & $74 \pm 1.12$ & $\begin{array}{l}1247 \pm 8 \\
9.6\end{array}$ & $\begin{array}{l}1.32 \pm 0 \\
.04\end{array}$ & $\begin{array}{l}0.874 \pm 0 \\
04\end{array}$ & $\begin{array}{l}4.25 \pm \\
0.16\end{array}$ & $6.02 \pm 0.14$ & $\begin{array}{l}78.00 \pm 4 \\
.28\end{array}$ \\
\hline F8 & 10 & 15 & 300 & 2 & $\begin{array}{l}81 \pm 0 . \\
93\end{array}$ & $\begin{array}{l}988 \pm 29 \\
4\end{array}$ & $\begin{array}{l}2.984 \pm \\
0.07\end{array}$ & $\begin{array}{l}1.847 \pm 0 \\
01\end{array}$ & $\begin{array}{l}3.57 \pm \\
0.13\end{array}$ & $3.04 \pm 0.09$ & $\begin{array}{l}64.50 \pm 3 \\
.85\end{array}$ \\
\hline F9 & 10 & 5 & 1100 & 2 & $62 \pm 0.89$ & $\begin{array}{l}627 \pm 42 \\
8\end{array}$ & $\begin{array}{l}1.982 \pm \\
0.08\end{array}$ & $\begin{array}{l}1.87 \pm 0.1 \\
0\end{array}$ & $\begin{array}{l}5.64 \pm \\
0.14\end{array}$ & $4.02 \pm 0.08$ & $\begin{array}{l}64.36 \pm 2 \\
.18\end{array}$ \\
\hline F10 & 5 & 10 & 700 & 1 & $81 \pm 1.36$ & $\begin{array}{l}872 \pm 35 \\
9\end{array}$ & $\begin{array}{l}2.057 \pm \\
0.10\end{array}$ & $\begin{array}{l}1.247 \pm 0 \\
12\end{array}$ & $\begin{array}{l}1.02 \pm \\
0.02\end{array}$ & $1.02 \pm 0.05$ & $\begin{array}{l}62.27 \pm 2 \\
.45\end{array}$ \\
\hline F11 & 15 & 10 & 1500 & 1 & $44 \pm 0.78$ & $\begin{array}{l}1054 \pm 4 \\
1.3\end{array}$ & $\begin{array}{l}1.254 \pm \\
0.09\end{array}$ & $\begin{array}{l}0.334 \pm 0 \\
09\end{array}$ & $\begin{array}{l}2.78 \pm \\
0.06\end{array}$ & $8.92 \pm 0.17$ & $\begin{array}{l}64.70 \pm 3 \\
.84\end{array}$ \\
\hline F12 & 15 & 20 & 1500 & 1 & $38 \pm 0.93$ & $\begin{array}{l}1647 \pm 4 \\
8.7\end{array}$ & $\begin{array}{l}0.998 \pm \\
0.08\end{array}$ & $\begin{array}{l}0.18 \pm 0.0 \\
7\end{array}$ & $\begin{array}{l}2.55 \pm \\
0.08\end{array}$ & $4.65 \pm 0.15$ & $\begin{array}{l}77.00 \pm 3 \\
.63\end{array}$ \\
\hline F13 & 15 & 20 & 700 & 3 & $52 \pm 1.36$ & $\begin{array}{l}1478 \pm 9 \\
3.5\end{array}$ & $\begin{array}{l}2.047 \pm \\
0.11\end{array}$ & $\begin{array}{l}0.145 \pm 0 . \\
08\end{array}$ & $\begin{array}{l}6.72 \pm \\
0.18\end{array}$ & $2.54 \pm 0.08$ & $\begin{array}{l}81.45 \pm 5 \\
.23\end{array}$ \\
\hline F14 & 15 & 20 & 1500 & 3 & $14 \pm 0.68$ & $\begin{array}{l}1247 \pm 8 \\
9.5\end{array}$ & $\begin{array}{l}0.874 \pm \\
0.09\end{array}$ & $\begin{array}{l}0.34 \pm 0.0 \\
2\end{array}$ & $\begin{array}{l}5.87 \pm \\
0.17\end{array}$ & $2.04 \pm 0.07$ & $\begin{array}{l}80.45 \pm 3 \\
.47\end{array}$ \\
\hline F15 & 5 & 10 & 1500 & 1 & $62 \pm 0.74$ & $\begin{array}{l}647 \pm 37 \\
1\end{array}$ & $\begin{array}{l}1.054 \pm \\
0.06\end{array}$ & $\begin{array}{l}1.14 \pm 0.1 \\
0\end{array}$ & $\begin{array}{l}0.24 \pm \\
0.01\end{array}$ & $3.05 \pm 0.06$ & $\begin{array}{l}70.58 \pm 2 \\
.63\end{array}$ \\
\hline F16 & 15 & 10 & 700 & 1 & $37 \pm 1.38$ & $\begin{array}{l}1242 \pm 9 \\
8.7\end{array}$ & $\begin{array}{l}1.354 \pm \\
0.08\end{array}$ & $\begin{array}{l}0.744 \pm 0 \\
05\end{array}$ & $\begin{array}{l}0.14 \pm \\
0.03\end{array}$ & $2.57 \pm 0.05$ & $\begin{array}{l}69.38 \pm 2 \\
.88\end{array}$ \\
\hline F17 & 5 & 10 & 1500 & 3 & $79 \pm 0.89$ & $\begin{array}{l}607 \pm 45 \\
8\end{array}$ & $\begin{array}{l}1.024 \pm \\
0.05\end{array}$ & $\begin{array}{l}0.247 \pm 0 \\
06\end{array}$ & $\begin{array}{l}7.21 \pm \\
0.19\end{array}$ & $4.98 \pm 0.03$ & $\begin{array}{l}67.64 \pm 3 \\
.14\end{array}$ \\
\hline F18 & 15 & 10 & 700 & 3 & $48 \pm 1.21$ & $\begin{array}{l}784 \pm 25 . \\
3\end{array}$ & $\begin{array}{l}2.047 \pm \\
0.13\end{array}$ & $\begin{array}{l}1.685 \pm 0 \\
03\end{array}$ & $\begin{array}{l}8.21 \pm \\
0.14\end{array}$ & $1.98 \pm 0.02$ & $\begin{array}{l}69.38 \pm 3 \\
.33\end{array}$ \\
\hline F19 & 10 & 15 & 1900 & 2 & $32 \pm 1.10$ & $\begin{array}{l}1104 \pm 8 \\
3.5\end{array}$ & $\begin{array}{l}0.974 \pm \\
0.06\end{array}$ & $\begin{array}{l}0.11 \pm 0.0 \\
5\end{array}$ & $\begin{array}{l}3.54 \pm \\
0.12\end{array}$ & $4.8 \pm 0.11$ & $\begin{array}{l}68.57 \pm 2 \\
.56\end{array}$ \\
\hline F20 & 10 & 15 & 1100 & 2 & $58 \pm 0.87$ & $\begin{array}{l}1547 \pm 4 \\
8.2\end{array}$ & $\begin{array}{l}0.887 \pm \\
0.05\end{array}$ & $\begin{array}{l}0.854 \pm 0 \\
07\end{array}$ & $\begin{array}{l}1.47 \pm \\
0.09\end{array}$ & $6.2 \pm 0.14$ & $\begin{array}{l}78.57 \pm 3 \\
.47\end{array}$ \\
\hline F21 & 5 & 20 & 1500 & 3 & $30 \pm 0.93$ & $\begin{array}{l}957 \pm 36 \\
5\end{array}$ & $\begin{array}{l}1.247 \pm \\
0.12\end{array}$ & $\begin{array}{l}0.047 \pm 0 \\
05\end{array}$ & $\begin{array}{l}6.59 \pm \\
0.18\end{array}$ & $1.02 \pm 0.02$ & $\begin{array}{l}62.67 \pm 2 \\
.56\end{array}$ \\
\hline F22 & 5 & 20 & 700 & 1 & $40 \pm 0.12$ & $\begin{array}{l}788 \pm 23 \\
5\end{array}$ & $\begin{array}{l}0.924 \pm \\
0.06\end{array}$ & $\begin{array}{l}1.958 \pm 0 . \\
03\end{array}$ & $\begin{array}{l}1.02 \pm \\
0.07\end{array}$ & $1.04 \pm 0.08$ & $\begin{array}{l}66.30 \pm 3 \\
.17\end{array}$ \\
\hline F23 & 10 & 15 & 1100 & 0 & $55 \pm 0.82$ & $\begin{array}{l}1068 \pm 7 \\
8.2\end{array}$ & $\begin{array}{l}0.847 \pm \\
0.08\end{array}$ & $\begin{array}{l}0.685 \pm 0 \text {. } \\
07\end{array}$ & $\begin{array}{l}1.03 \pm \\
0.05\end{array}$ & $4.6 \pm 0.13$ & $\begin{array}{l}78.57 \pm 2 \\
.66\end{array}$ \\
\hline F24 & 15 & 20 & 700 & 1 & $21 \pm 0.56$ & $\begin{array}{l}809 \pm 61 \\
3\end{array}$ & $\begin{array}{l}0.742 \pm \\
0.07\end{array}$ & $\begin{array}{l}0.882 \pm 0 \\
08\end{array}$ & $\begin{array}{l}1.62 \pm \\
0.06\end{array}$ & $7.6 \pm 0.18$ & $\begin{array}{l}78.25 \pm 2 \\
.87\end{array}$ \\
\hline F25 & 0 & 15 & 1100 & 2 & $68 \pm 0.84$ & $\begin{array}{l}708 \pm 52 \\
5\end{array}$ & $\begin{array}{l}1.624 \pm \\
0.10\end{array}$ & $\begin{array}{l}1.432 \pm 0 \\
06\end{array}$ & $\begin{array}{l}4.21 \pm \\
0.14\end{array}$ & $5.2 \pm 0.15$ & $\begin{array}{l}57.92 \pm 2 \\
.55\end{array}$ \\
\hline F26 & 10 & 25 & 1100 & 2 & $23 \pm 0.18$ & $\begin{array}{l}1467 \pm 8 \\
3.4\end{array}$ & $\begin{array}{l}0.975 \pm \\
0.08\end{array}$ & $\begin{array}{l}0.426 \pm 0 \\
09\end{array}$ & $\begin{array}{l}5.21 \pm \\
0.13\end{array}$ & $0.98 \pm 0.05$ & $\begin{array}{l}66.00 \pm 2 \\
.33\end{array}$ \\
\hline F27 & 15 & 10 & 1500 & 3 & $57 \pm 0.47$ & $\begin{array}{l}938 \pm 41 . \\
8\end{array}$ & $\begin{array}{l}0.827 \pm \\
0.09\end{array}$ & $\begin{array}{l}1.057 \pm 0 \\
05\end{array}$ & $\begin{array}{l}6.14 \pm \\
0.11\end{array}$ & $5.1 \pm 0.18$ & $\begin{array}{l}64.70 \pm 3 \\
.11\end{array}$ \\
\hline F28 & 5 & 10 & 700 & 3 & $89 \pm 0.86$ & $\begin{array}{l}805 \pm 30 \\
2\end{array}$ & $\begin{array}{l}1.547 \pm \\
0.05\end{array}$ & $\begin{array}{l}1.675 \pm 0 \\
08\end{array}$ & $\begin{array}{l}5.99 \pm \\
0.18\end{array}$ & $2.04 \pm 0.04$ & $\begin{array}{l}71.31 \pm 2 \\
.52\end{array}$ \\
\hline F29 & 10 & 15 & 1100 & 2 & $51 \pm 0.58$ & $\begin{array}{l}1226 \pm 2 \\
3.4\end{array}$ & $\begin{array}{l}0.993 \pm \\
0.03\end{array}$ & $\begin{array}{l}1.662 \pm 0 \\
07\end{array}$ & $\begin{array}{l}7.01 \pm \\
0.17\end{array}$ & $6.87 \pm 0.12$ & $\begin{array}{l}78.00 \pm 2 \\
.89\end{array}$ \\
\hline F30 & 20 & 15 & 1100 & 2 & $56 \pm 0.96$ & $\begin{array}{l}1537 \pm 8 \\
6.3\end{array}$ & $\begin{array}{l}1.427 \pm \\
0.13\end{array}$ & $\begin{array}{l}1.24 \pm 0.1 \\
0\end{array}$ & $\begin{array}{l}4.25 \pm \\
0.08\end{array}$ & $5.1 \pm 0.14$ & $\begin{array}{l}69.50 \pm 2 \\
.49\end{array}$ \\
\hline
\end{tabular}

\footnotetext{
*All values represent mean \pm standard deviation $(n=3)$
} 
Table 2: Design summary for 30 runs with quadratic and 2FI as design models

\begin{tabular}{|c|c|c|c|c|c|c|c|c|c|}
\hline Factor & Name & Units & Type & Low actual & High actual & Low coded & High coded & Mean & Std. dev. \\
\hline $\mathrm{A}$ & Amount of Methyl Cellulose & $\%$ & Numeric & 5 & 15 & -1 & 1 & 10 & 4.472136 \\
\hline $\mathrm{B}$ & Amount of PEG 6000 & $\%$ & Numeric & 10 & 20 & -1 & 1 & 15 & 4.472136 \\
\hline $\mathrm{C}$ & Spheronization speed & $\mathrm{rpm}$ & Numeric & 700 & 1500 & -1 & 1 & 1100 & 357.7709 \\
\hline $\mathrm{D}$ & Croscarmellose sodium & $\%$ & Numeric & 1 & 3 & -1 & 1 & 2 & 0.894427 \\
\hline
\end{tabular}

All values represent mean \pm standard deviation $(n=3)$

\section{Theoretical yield}

Correlation of Theoretical Yield with Amount of Methyl Cellulose (0.396), Amount of PEG 6000 (-0.543), Spheronization speed $(-0.364)$ and Croscarmellose sodium (0.190) was shown in fig. 1. Amount of Methyl Cellulose, Amount of PEG 6000, Spheronization speed rate shows negative correlation as Amount of Croscarmellose sodium shows a positive correlation.

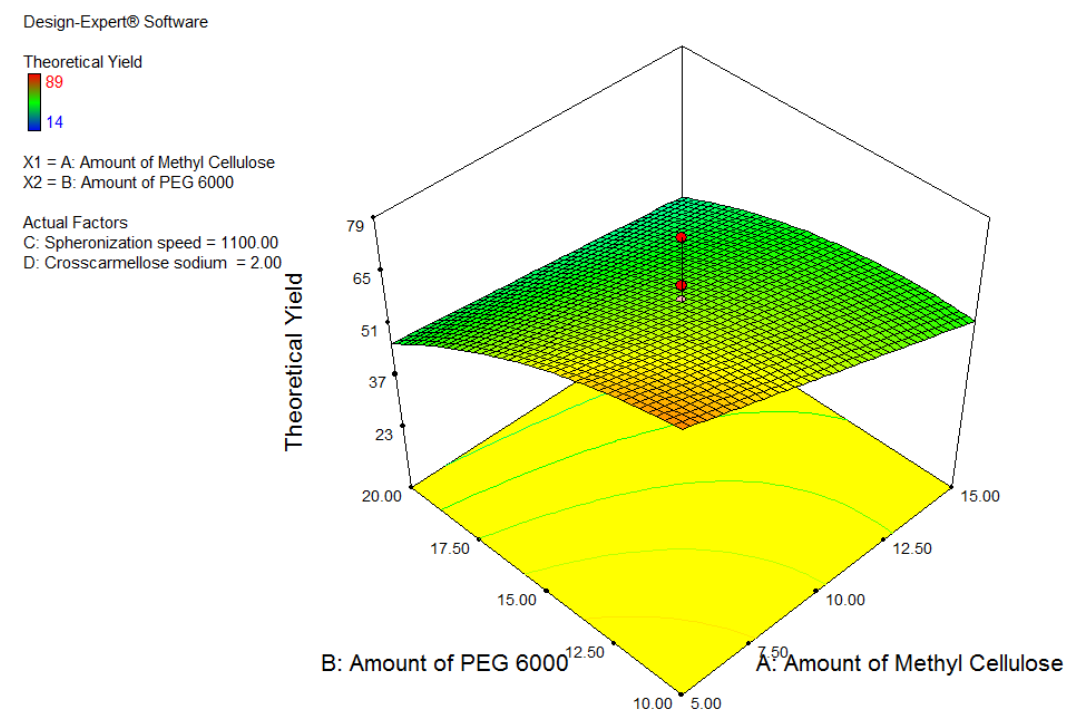

Fig. 1: Response surface graph for theoretical yield with respect to the amount of PEG 6000 and methylcellulose as prominent factors

From this, it was concluded that there was a negative effect of Amount of Methyl Cellulose, Amount of PEG 6000, Spheronization speed rate and positive effect of Croscarmellose sodium on the Theoretical Yield. Final Equation in Terms of Coded Factors:

Theoretical Yield $=59.16667-8.33333 * \mathrm{~A}-11.4167 * \mathrm{~B}-7.66667 * \mathrm{C}+4$ * D+4.625*A * B+4.75*A*C-1.625*A*D-3.75*B *C-0.625*B * D-5 * C * D-0.0625*A2-4.9375*B2-1.4375* C2-1.3125* D2

\section{Mean pellet size}

Correlation of mean pellet size with the amount of Methyl Cellulose (0.571), amount of PEG 6000 (0.359), Spheronization speed (0.079) and Croscarmellose sodium (-0.091) was shown in fig. 2. Amount of Methyl Cellulose, Amount of PEG 6000, Spheronization speed rate shows positive correlation as Amount of Croscarmellose sodium shows a negative correlation.

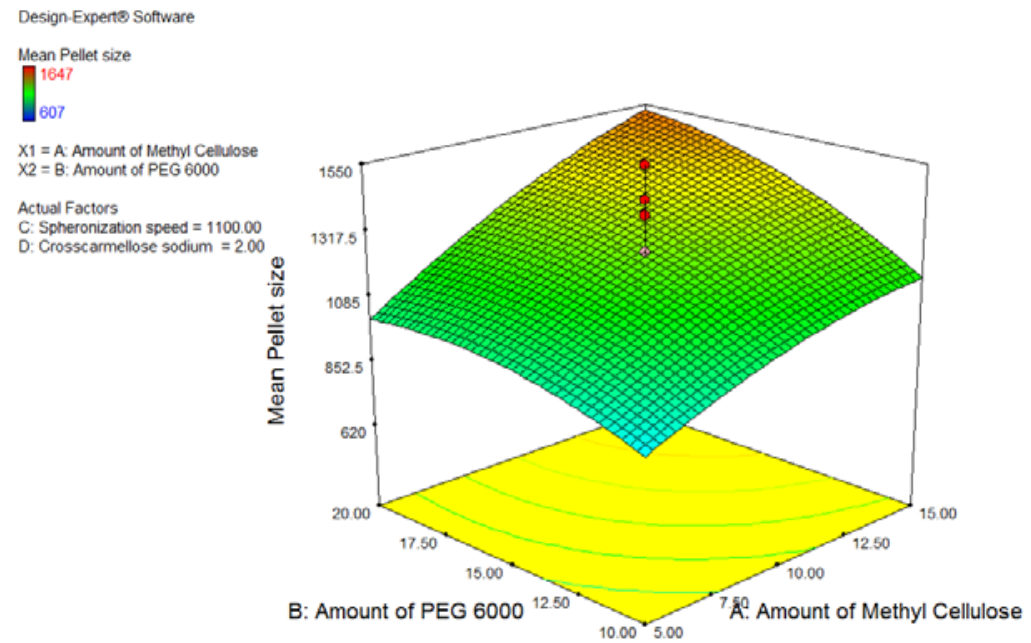

Fig. 2: Response surface graph for mean pellet size with respect to amount of PEG 6000 and methylcellulose as prominent factors 
From this, it was concluded that there was a positive effect of Amount of Methyl Cellulose, Amount of PEG 6000, Spheronization speed rate and negative effect of Croscarmellose sodium on the mean pellet size. In this case, A and B are significant model terms. Final Equation in Terms of Coded Factors:

Mean Pellet size $=1261+200.5416667 * A+126.0416667 *$ $\mathrm{B}+27.70833333 * \mathrm{C}-31.875 * \mathrm{D}+61.3125 * \mathrm{~A} * \mathrm{~B}+44.5625 * \mathrm{~A} * \mathrm{C}-$ $15.8125 * \mathrm{~A} * \mathrm{D}+84.1875 * \mathrm{~B} * \mathrm{C}+62.8125 * \mathrm{~B} * \mathrm{D}-20.1875 * \mathrm{C} * \mathrm{D}-$ $50.07291667 *$ A2-68.94791667 * B2-69.19791667*C2$89.19791667 * \mathrm{D} 2$

\section{Sphericity (pellips)}

Correlation of Sphericity with Amount of Methyl Cellulose ($0.080)$, Amount of PEG $6000(-0.248)$, Spheronization speed (-
0.623) and Croscarmellose sodium (0.235) was shown in fig. 3. Amount of Methyl Cellulose, Amount of PEG 6000, Spheronization speed rate shows negative correlation as Amount of Croscarmellose sodium shows a positive correlation. From this, it was concluded that there was a negative effect of Amount of Methyl Cellulose, Amount of PEG 6000, Spheronization speed rate and positive effect of Croscarmellose sodium on the Sphericity. In this case, CandC $\mathrm{C}^{2}$ are significant model terms. Final Equation in Terms of Coded Factors:

Sphericity (pellips) $=1.241-0.045375 *$ A-0.140041667 * B$0.352041667 * \mathrm{C}+0.132541667 * \mathrm{D}-0.0184375 * \mathrm{~A} * \mathrm{~B}-0.0028125 *$ $\mathrm{A} * \mathrm{C}+0.0421875 * \mathrm{~A} * \mathrm{D}+0.0789375 * \mathrm{~B} * \mathrm{C}+0.1729375 * \mathrm{~B} * \mathrm{D}-$ $0.1801875 * \quad \mathrm{C} \quad * \quad \mathrm{D}+0.036739583 * \quad \mathrm{~A} 2+0.024989583$ *B2+0.150114583* $\mathrm{C} 2-0.072760417 * \mathrm{D} 2$

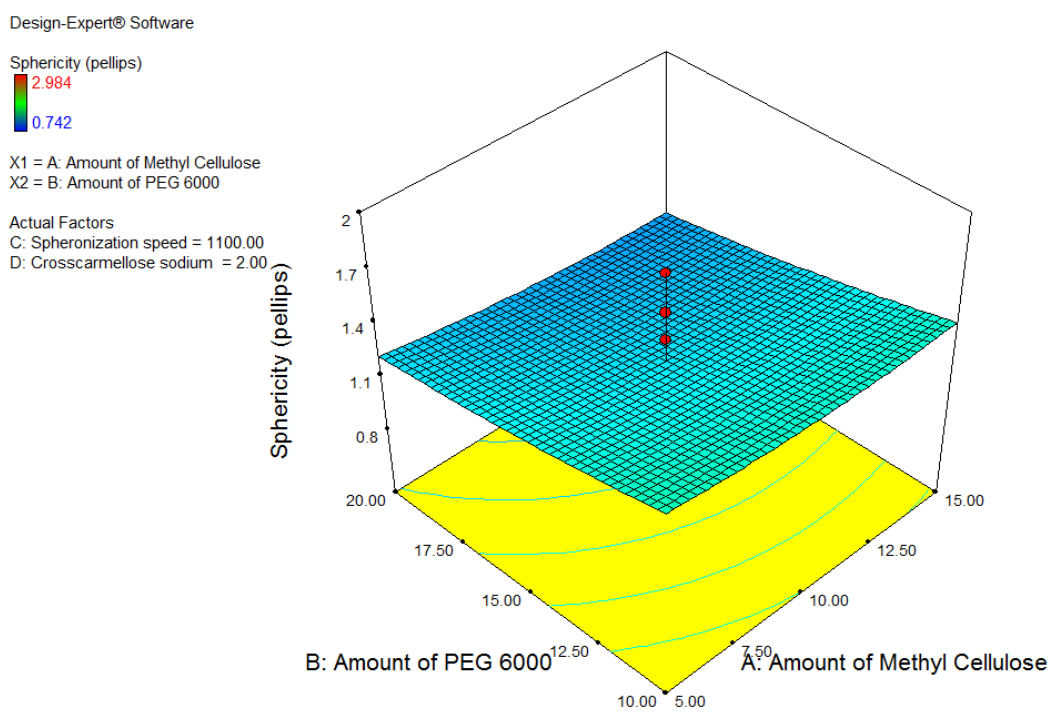

Fig. 3: Response surface graph for sphericity (pellips) with respect to the Amount of PEG 6000 and Methylcellulose as prominent factors

\section{Friability}

Correlation of Friability with Amount of Methyl Cellulose (-0.139), Amount of PEG 6000 (-0.425), Spheronization speed (-0.569) and Croscarmellose sodium $(-0.083)$ was shown in fig. 4. Amount of Methyl Cellulose, Amount of PEG 6000, Spheronization speed rate and Amount of Croscarmellose shows a negative correlation. From this, it was concluded that there was a negative effect of Amount of Methyl Cellulose, Amount of PEG 6000, Spheronization speed rate and Croscarmellose sodium on the Friability. In this case, B and C are significant model terms. Final Equation in Terms of Coded Factors:

Friability $=0.977666667-0.090041667 * \mathrm{~A}-0.276458333 * \mathrm{~B}-$ $0.369791667 * \mathrm{C}-0.053875 * \mathrm{D}-0.0499375 * \mathrm{~A} * \mathrm{~B}+0.1444375 * \mathrm{~A} *$ $\mathrm{C}+0.1908125 * \mathrm{~A} * \mathrm{D}-0.0159375 * \mathrm{~B} * \mathrm{C}-2048125 * \mathrm{~B} * \mathrm{D}+0.0333125$ $* \mathrm{C} * \mathrm{D}+0.05140625 * \mathrm{~A} 2+0.00440625 * \mathrm{~B} 2-0.03796875 * \mathrm{C} 2-$ $0.13721875^{*} \mathrm{D} 2$.

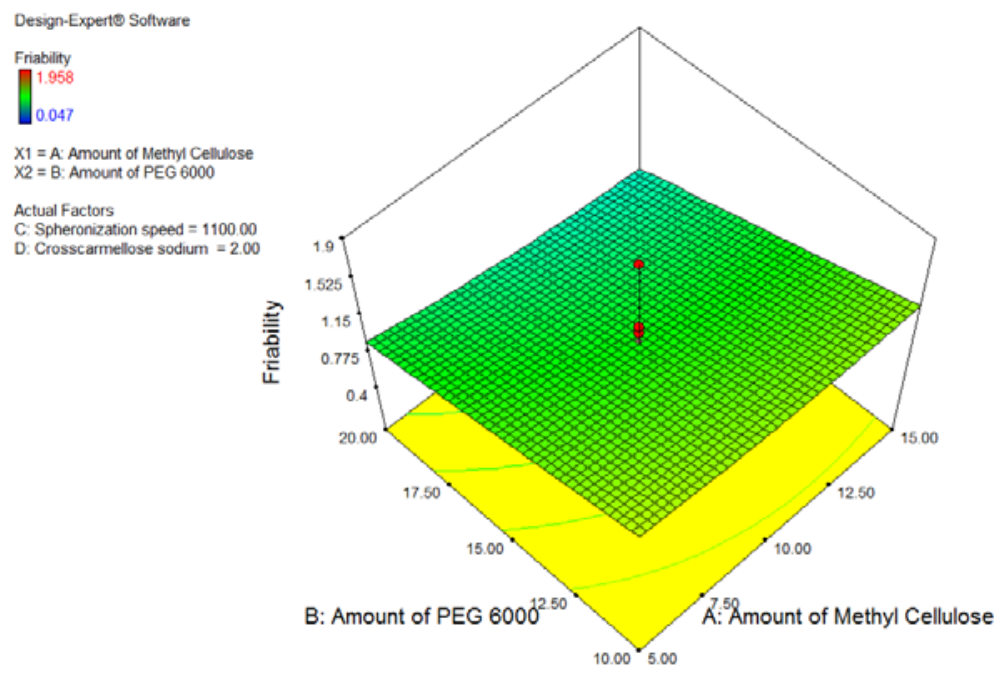

Fig. 4: Response surface graph for friability with respect to Amount of PEG 6000 and Methylcellulose as prominent factors 


\section{Porosity}

Correlation of Porosity with Amount of Methyl Cellulose (-0.396), Amount of PEG 6000 (-0.543), Spheronization speed (-0.364) and Croscarmellose sodium ( 0.190 was shown in fig. 5. Amount of Methyl Cellulose, Amount of PEG 6000, Spheronization speed rate shows negative correlation as Amount of Croscarmellose sodium shows a positive correlation. From this, it was concluded that there was a negative effect of Amount of Methyl Cellulose, Amount of PEG
6000, Spheronization speed rate and positive effect of Croscarmellose sodium on the Porosity. In this case, D is a significant model term. Final Equation in Terms of Coded Factors:

Porosity $=3.533333333+0.282916667 * \mathrm{~A}-0.12375^{*}$ $\mathrm{B}+0.142916667 * \mathrm{C}+2.037083333 * \mathrm{D}+0.068125 * \mathrm{~A} * \mathrm{~B}-0.136875 *$ $\mathrm{A} * \mathrm{C}-0.051875 * \mathrm{~A} * \mathrm{D}+0.091875 * \mathrm{~B} * \mathrm{C}-0.388125 * \mathrm{~B} * \mathrm{D}-0.133125$

* $\mathrm{C} * \mathrm{D}+0.1328125 * \mathrm{~A} 2+0.4315625 * \mathrm{~B} 2-0.0359375 * \mathrm{C} 2-$ $0.1446875 * \mathrm{D} 2$

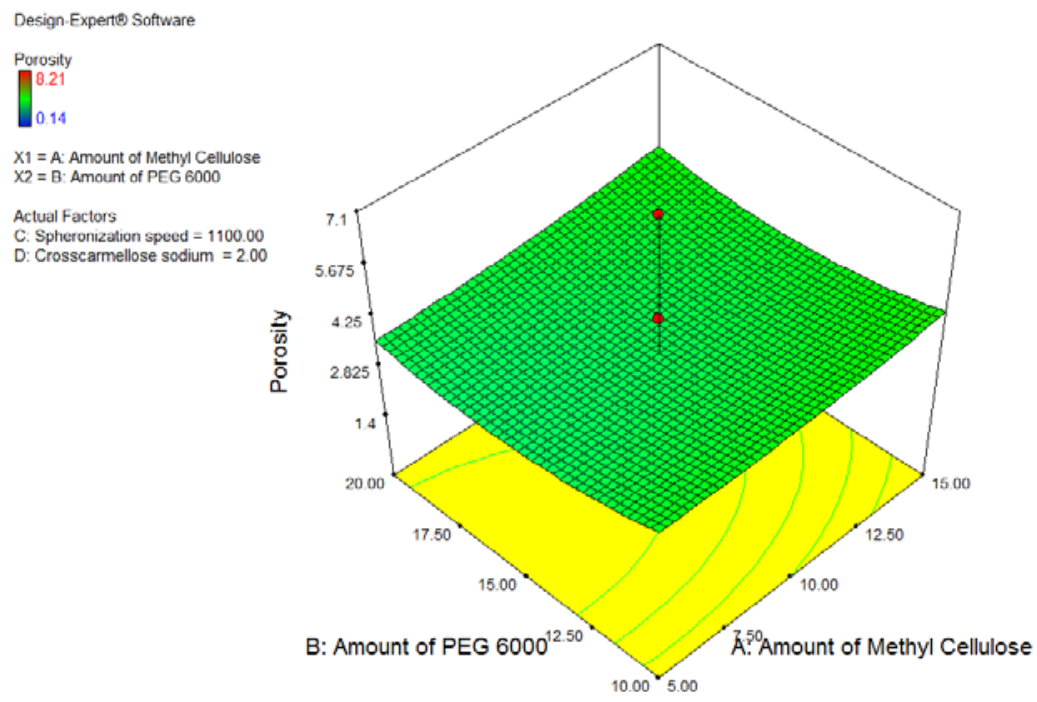

Fig. 5: Response surface graph for porosity with respect to amount of PEG 6000 and methylcellulose as prominent factors

\section{Mechanical crushing force}

Correlation of Mechanical crushing force with Amount of Methyl Cellulose (0.338), Amount of PEG 6000 (-0.243), Spheronization speed $(-0.238)$ and Croscarmellose sodium $(-0.161)$ was shown in fig. 6. Amount of Croscarmellose sodium, Amount of PEG 6000, Spheronization speed rate shows negative correlation as Amount of Methyl Cellulose shows a positive correlation. From this, it was concluded that there was a negative effect of Amount of
Croscarmellose sodium, Amount of PEG 6000, Spheronization speed rate and positive effect of Amount of Methyl Cellulose on the Mechanical crushing force. The cubic model was aliased. In this case, $\mathrm{A}, \mathrm{AD}, \mathrm{BC}$ is a significant model terms. Final Equation in Terms of Coded Factors:

Mechanical crushing force $=3.787666667+0.769166667 * \mathrm{~A}-$ $0.5525 * \mathrm{~B}+0.541666667 * \mathrm{C}-0.3675 * \mathrm{D}+0.23125 * \mathrm{~A} * \mathrm{~B}+0.16 * \mathrm{~A} * \mathrm{C}-$ $1.03125 * A * D-1.2125 * B * C-0.29625 * B$ D- $0.0875 * C * D$

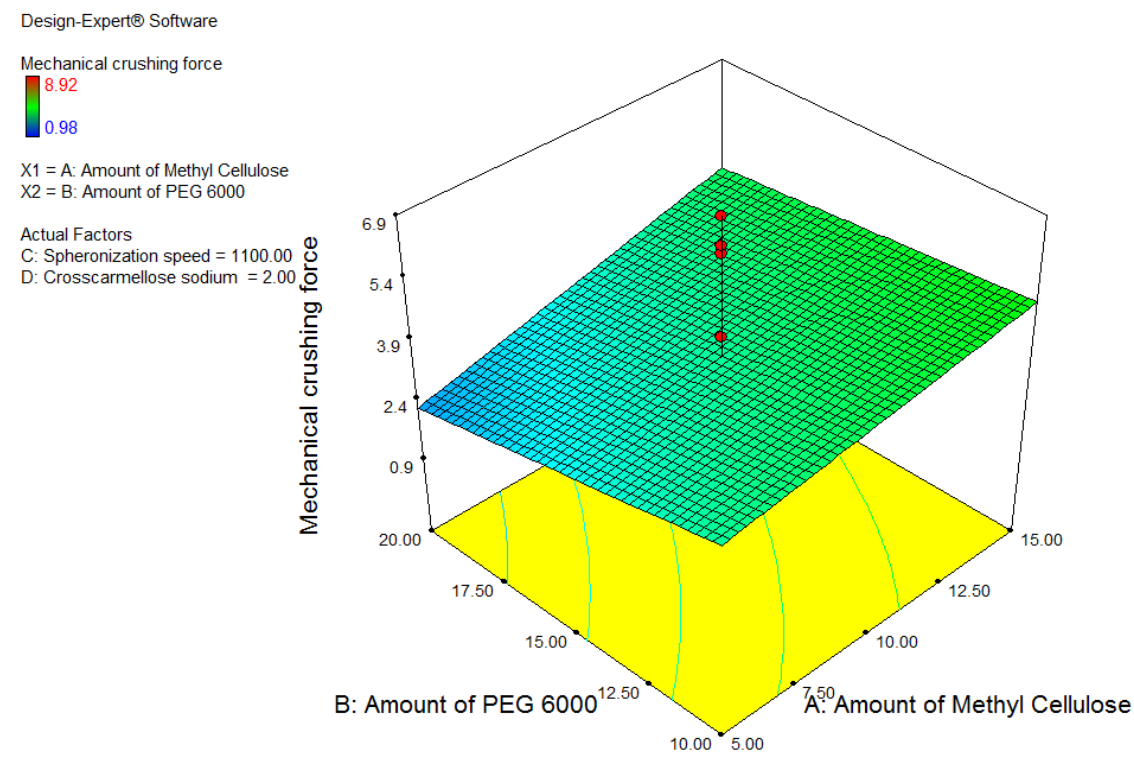

Fig. 6: Response surface graph for mechanical crushing force with respect to amount of PEG 6000 and methylcellulose as prominent factors 


\section{Drug release}

The in vitro drug release data from the different formulations were evaluated kinetically using the Korsmeyer-Peppas, Weibull and HixsonCrowell models. The coefficient of determination (R2), root-meansquare error (RMSE) and Akaike's information criterion (AIC) values of these models were determined for evaluation of accuracy and prediction ability of these models using Kinet DS 3.0 rev. 2010 software (Krakow, Poland). From the obtained results, it is observed that for all formulations the drug release mechanism is best described by Korsmeyer-Peppas model. The release exponent (n) is used in order to characterize different release mechanism. Correlation of Dissolution efficiency with Amount of Methyl Cellulose (0.277), Amount of PEG 6000
(0.383), Spheronization speed (0.022) and Croscarmellose sodium (0.036 ) was shown in fig. 7. Amount of Methyl Cellulose, amount of PEG 6000 and Spheronization speed rate shows positive correlation as Amount of Croscarmellose sodium shows a negative correlation. From this, it was concluded that there was a positive effect of Amount of Amount of PEG 6000, Spheronization speed rate and negative effect of Croscarmellose sodium on the Dissolution efficiency. The cubic model was aliased. In this case, $\mathrm{B}, \mathrm{A}^{2}, \mathrm{~B}^{2}, \mathrm{C}^{2}$ are significant model terms. Final Equation in Terms of Coded Factors:

Dissolution Efficiency $=+77.52+2.05 * \mathrm{~A}+2.83 * \mathrm{~B}+0.16 * \mathrm{C}-0.26 *$ $\mathrm{D}+2.08 * \mathrm{~A} * \mathrm{~B}-1.18 * \mathrm{~A} * \mathrm{C}+0.66 * \mathrm{~A} * \mathrm{D}+0.32 * \mathrm{~B} * \mathrm{C}-0.59 * \mathrm{~B} * \mathrm{D}-$ $2.58 * C * \mathrm{D}-2.85 * \mathrm{~A} 2-2.48 * \mathrm{~B} 2-2.14 * \mathrm{C} 2+0.29 * \mathrm{D} 2$

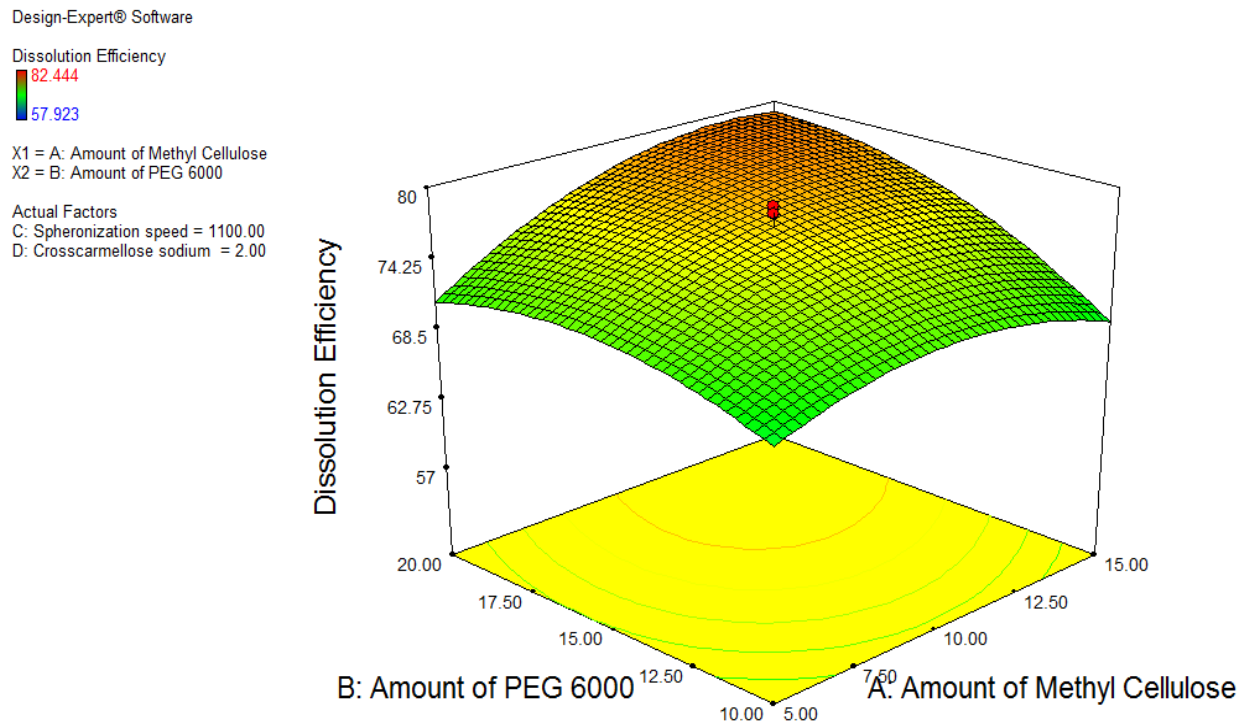

Fig. 7: Response surface graph for dissolution efficiency with respect to amount of PEG 6000 and methylcellulose as prominent factors

\section{Release kinetic}

Fig. 8 shows in vitro drug release of all formulations. The correlation coefficient $\left(R^{2}\right)$ was found to be in between $\left(R^{2}\right)=$ 0.997 to 0.999 . By observing the regression values of various models, the Korsmeyer-Peppas with a lag model was found to be the best model for all formulation. The value of $\mathrm{n}$ in our formulations is between $0.77+0.04$ which characterizes the release mechanism of a drug as non-Fickian transport $(0.45<\mathrm{n}<0.89)$.

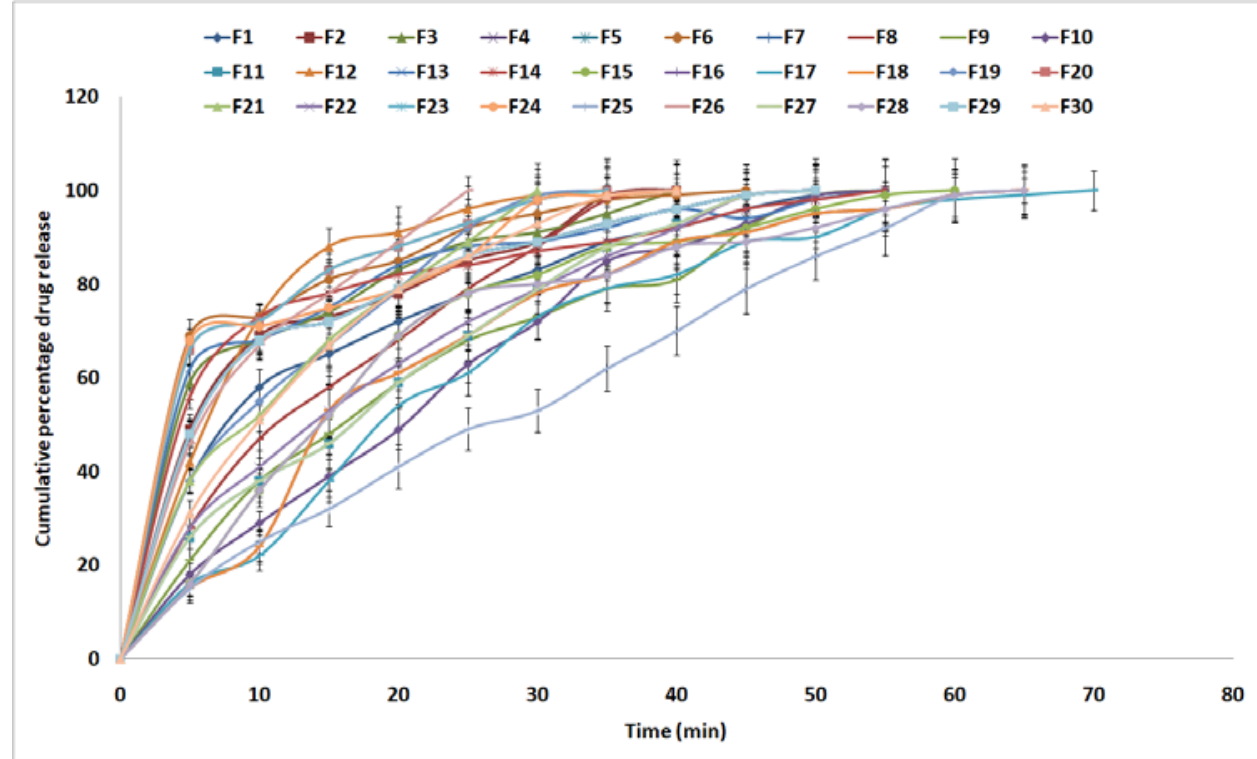

Fig. 8: Cumulative \% drug release studies of formulations (F1 to F30) 
Table 3: Summary of results of various micromeritic evaluation parameters and drug content of optimized immediate release pellets prepared

\begin{tabular}{ll}
\hline Evaluation parameter & Pellets \pm SD \\
\hline Bulk density $\left(\mathrm{g} / \mathrm{cm}^{3}\right)$ & $0.4928 \pm 0.0505$ \\
Tapped density $\left(\mathrm{g} / \mathrm{cm}^{3}\right)$ & $0.8333 \pm 0.0396$ \\
Carr's index $(\%$ compressibility) & $11.2179 \pm 0.6202$ \\
Hausner's ratio (RH) & $23.0733 \pm 0.3847$ \\
Angle of repose (degree) & $27.8215 \pm 0.6161$ \\
Drug content $(\%)$ & $97.1 \pm 1.80$ \\
\hline
\end{tabular}

*All values represent mean \pm standard deviation $(n=3)$

Results of various micromeritic evaluation parameters and drug content of optimized immediate release pellets prepared are summarized in table 3.

\section{Experimental parameters}

The extruder used is of the axial-type single-screw feeder and hence generates heat due to the friction of the screw feeder with the wall of the extruder. Thus, varying the speed of the extruder to either medium or low resulted in drying of the wet blend within the extruder. Hence, the speed of extruder was fixed at maximum for a better output of extrusion. In this study, during preliminary trials, it was observed that initial high-speed spheronization is required to reduce the length of extrudes, but if the same speed is continued further, a greater amount of fines were generated. Hence, to reduce the generation of fines and achieve spherical pellets, spheronization speed and time could not be fixed at one value. Initial high speed followed by medium speed, enough to round off extrudes, was applied to manufacture pellets. The inability of extrudes to break at low spheronization speed can be the result of high drug content in wet mass. Moreover, the time required to spheronize the same was also higher than usual processing owing to less percent w/w of MCC in the formulation. It took more time to spheronize the cut extrudes with varying speed during the process. Moreover, high drug loading resulted in granules which were difficult to extrude when extrusion screen below $1 \mathrm{~mm}$ was used. Higher screen size resulted in high pellet diameter, and thus the extruder screen was fixed to $1 \mathrm{~mm}$.

\section{Excipients effect}

A spheronizing agent, such as a suitable grade of microcrystalline cellulose (MCC), is required to produce spherical pellets. MCC, being a spheronizing aid, highly affects sphericity along with a granulating solvent, i.e., water, which acts as a plasticizer. Hence, from preliminary trials, a minimum amount of MCC was identified which is required to impart sphericity to pellets, and disintegrants were added in order to improve the disintegration of pellets [20, 21]. PEG 6000 , being a binder, highly affected the friability and disintegration of pellets. Cross carmellose sodium, used as a super disintegrant, affected friability and disintegration time. During extrusion and spheronization, swelling of CCS was observed which was directly proportional to the quantity of CCS used in the formulation. The greater the proportion of CCS used, the greater the swelling, which finally led to the generation of more amount of fines during spheronization, irrespective of binder concentration. Moreover, it also reduced the disintegrant property of CCS when such batches were evaluated for DT. Thus, considering these effects, its range was fixed and the risk was mitigated [22].

\section{Validation of multiple response optimization models}

The formulation parameters of the optimum and the random checkpoints, their experimental and predicted values for all the seven response variables are listed in table 4 . The optimized Immediate release pellets were prepared with Amount of Methyl Cellulose (7.9\%), Amount of PEG 6000 (10\%), Spheronization speed (1492rpm) and Croscarmellose sodium (2.83\%). The optimized immediate release pellets were evaluated for all the physicomechanical properties using the methods mentioned earlier. The summary of the results of various physicomechanical evaluation parameters and drug content of immediate-release pellets are shown in table 4 . The experimental and predicted values for all the seven responses (Y1 to Y7) along with percentage prediction error* observed for optimum formulation (A) and random formulation (B and C).

Table 4: Percent prediction error (PE) was calculated using the formula (Experimental Value-Predicted Value)/Experimental Value) $\mathrm{x} 100$

\begin{tabular}{|c|c|c|c|c|c|c|c|c|c|}
\hline \multirow[t]{2}{*}{ Response } & \multicolumn{3}{|c|}{ A $(7.9,10,1492,2.83) \#$} & \multicolumn{3}{|c|}{ B $(14.83,10,1500,2.67) \#$} & \multicolumn{3}{|c|}{ C $(10.78,10,1491.67,2.52) \#$} \\
\hline & $\begin{array}{l}\text { Experimental } \\
\text { value }\end{array}$ & $\begin{array}{l}\text { Predicted } \\
\text { value }\end{array}$ & \% PE* & $\begin{array}{l}\text { Experimental } \\
\text { value }\end{array}$ & $\begin{array}{l}\text { Predicted } \\
\text { value }\end{array}$ & $\% \mathrm{PE}^{*}$ & $\begin{array}{l}\text { Experimental } \\
\text { value }\end{array}$ & $\begin{array}{l}\text { Predicted } \\
\text { value }\end{array}$ & $\% \mathrm{PE}^{*}$ \\
\hline $\begin{array}{l}\text { Theoretical } \\
\text { Yield }\end{array}$ & 63.89 & 63.30 & 0.92346 & 50.61 & 50.43 & 0.35566 & 58.94 & 58.51 & 0.7295555 \\
\hline Mean Pellet size & 707.85 & 706.36 & 0.2105 & 945.77 & 945.01 & 0.08036 & 886.99 & 886.91 & 0.0090193 \\
\hline $\begin{array}{l}\text { Sphericity } \\
\text { (pellips) }\end{array}$ & 0.901 & 0.90 & 0.11099 & 0.978 & 0.97 & 0.818 & 0.999 & 0.99 & 0.9009009 \\
\hline Friability & 0.836 & 0.83 & 0.7177 & 1.199 & 1.19 & 0.75063 & 0.968 & 0.96 & 0.8264463 \\
\hline Porosity & 5.927 & 5.92 & 0.1181 & 5.737 & 5.73 & 0.12201 & 5.288 & 5.26 & 0.5295008 \\
\hline $\begin{array}{l}\text { Mechanical } \\
\text { crushing force }\end{array}$ & 6.01 & 6 & 0.16639 & 6.02 & 6 & 0.33223 & 6.04 & 6 & 0.6622517 \\
\hline $\begin{array}{l}\text { Dissolution } \\
\text { Efficiency }\end{array}$ & 68.17 & 68.10 & 0.10268 & 65.32 & 65.11 & 0.32149 & 68.93 & 68.72 & 0.3046569 \\
\hline
\end{tabular}

*\#The values represented in the brackets are the Amount of Methyl Cellulose, Amount of PEG 6000, Spheronization speed and Croscarmellose sodium, respectively for $\mathrm{A}, \mathrm{B}$ and $\mathrm{C}$ formulations

\section{Compatibility study}

\section{Fourier transform infrared spectroscopy (FT-IR)}

FT-IR spectra of formulation showed the presence of all the principal peaks corresponding to the drug and polymers, they were with reduced transmittance and broader compared to those observed in the individual spectra. In addition, characteristic peak at 3, $435 \mathrm{~cm}-1$ correspondings to free $\mathrm{O}-\mathrm{H}$ stretching vibrations characteristic of a crystalline form of the drug was found to be absent in FT-IR spectra of the pellet. Presence of broadened principal peaks in FT-IR spectra with reduced transmittance suggested conversion of a crystalline form of the drug to amorphous form in extruded pellets. Similar observations were reported by Kim et al., 2008 also in the characterization of the crystalline and amorphous form (fig. 9) [23]. 


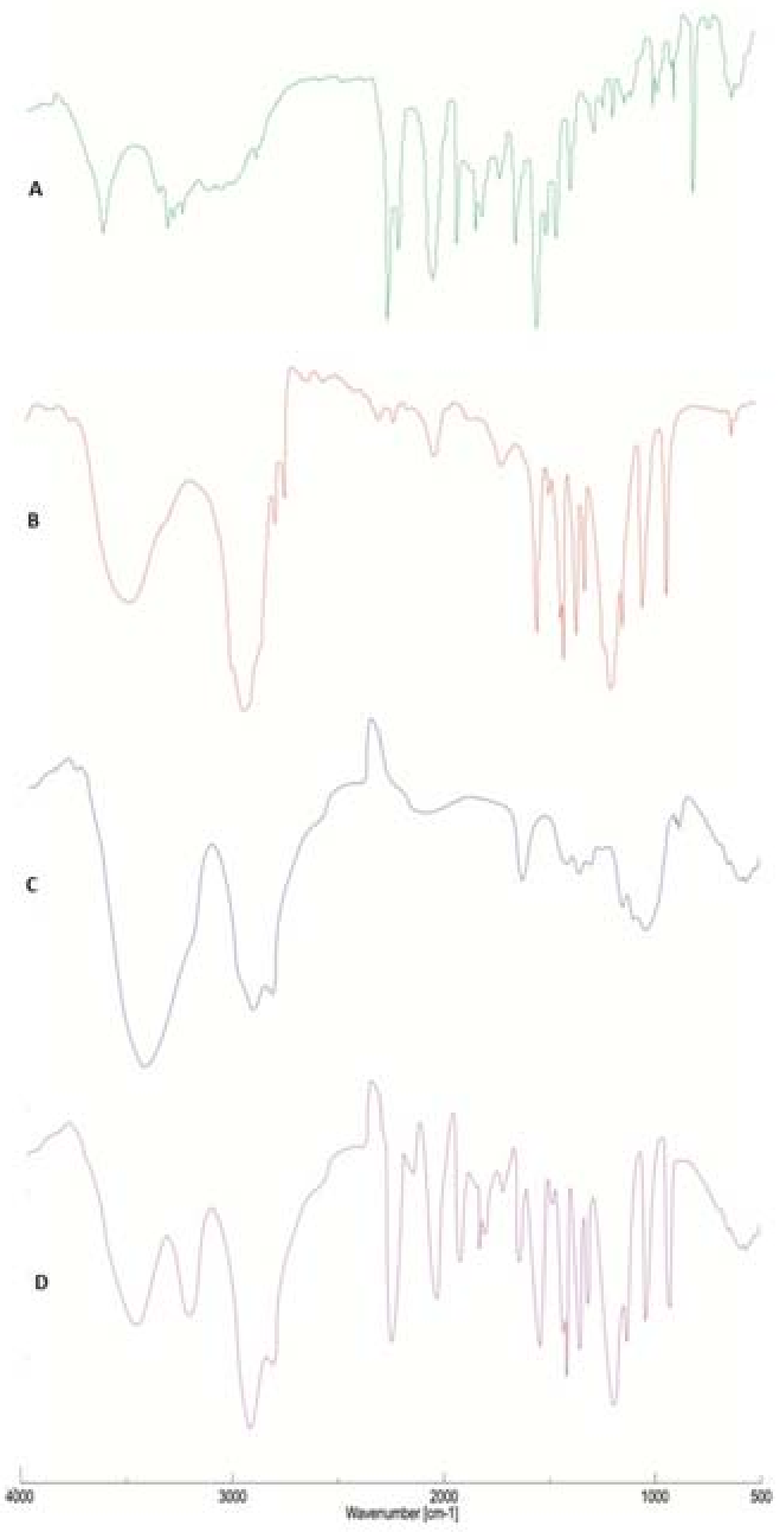

Fig. 9: FTIR spectra of A) Tamoxifen Citrate B) PEG 6000 C) Methyl Cellulose and D) Pellets

\section{Differential scanning calorimetry (DSC)}

In DSC study, there is the minor shifting of melting endotherm of the drug; hence it can be said that, there was no incompatibility of drug with any of the excipients [25, 26] (fig. 10).

\section{$X$-ray powder diffraction (XRPD)}

A distinct halo pattern and absence of principal diffraction peaks characteristic of crystalline TMC in XRPD profile of pellets confirmed that the drug was molecularly dispersed in the polymer matrix and the extrudates, so formed were homogeneous, amorphous solid solution system; supporting the predictions of thermal analysis. Whereas for broadened principal diffraction peaks suggested very fine 'crystallites' of the drug in the polymeric matrix and hence there was an insignificant degree of residual crystallinity in the extrudates. [27] Further, no new peaks could be observed, suggesting the absence of interaction between the drug and the carrier (fig. 11). 


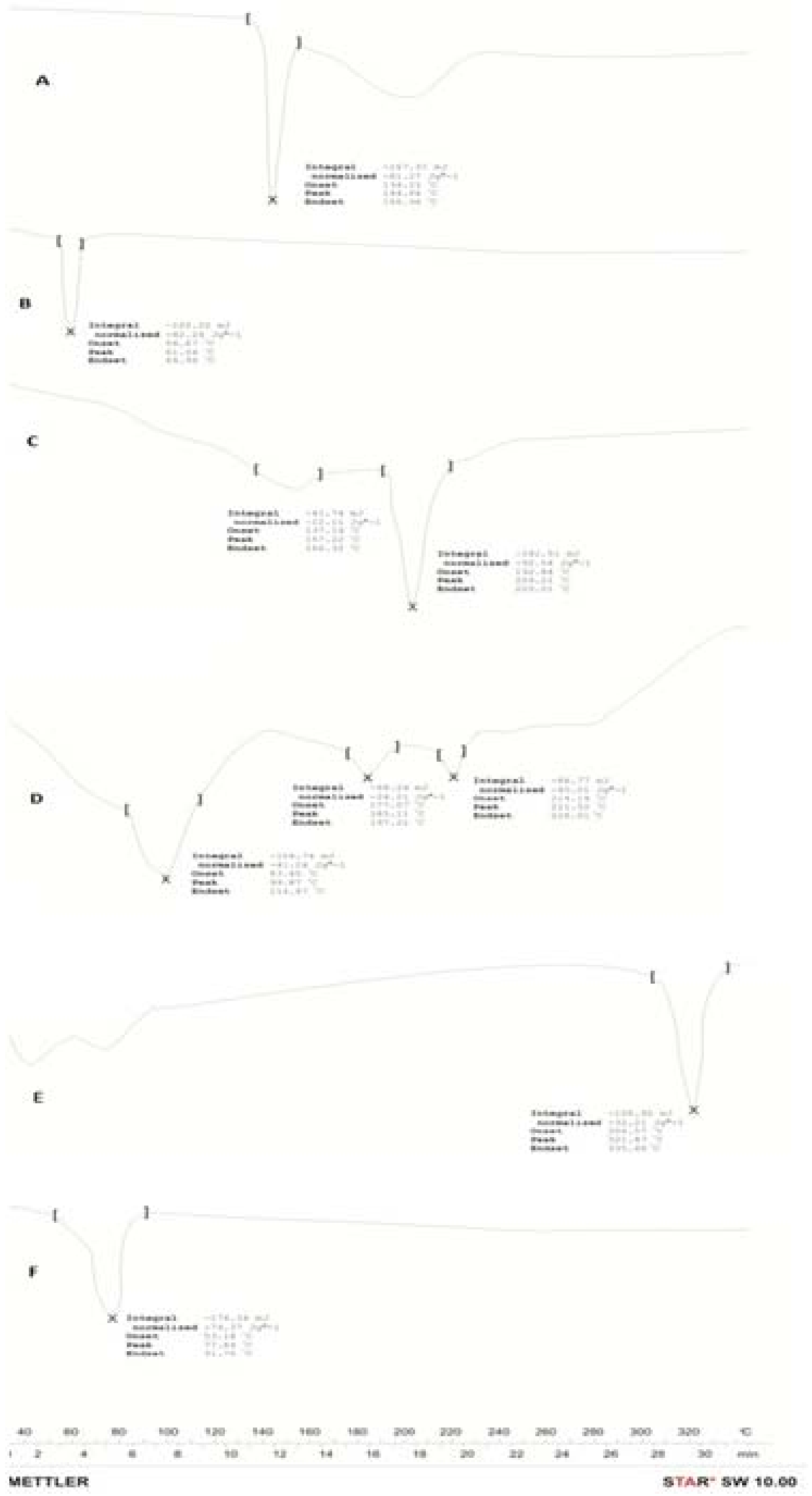

Fig. 10: DSC thermograph of A) Tamoxifen citrate B) PEG 6000 C) citric acid, D) methylcellulose E) microcrystalline cellulose and F) extruded pellets

\section{Scanning electron microscopy (SEM)}

Tamoxifen citrate 12a appeared as dense and agglomerate crystal. However, the photomicrographs extruded pellets $(12 \mathrm{~b}, 12 \mathrm{c}$, and 12d) appeared as spherical shape. These photomicrographs showed an absence of crystals of TMC as an entity and the particles rather appeared to be homogeneous. Dense, homogeneous appearance and absence of agglomerated crystals of $\mathrm{TMC}$ as an entity suggested uniform dispersions of TMC molecules into the extruded pellets [27] 

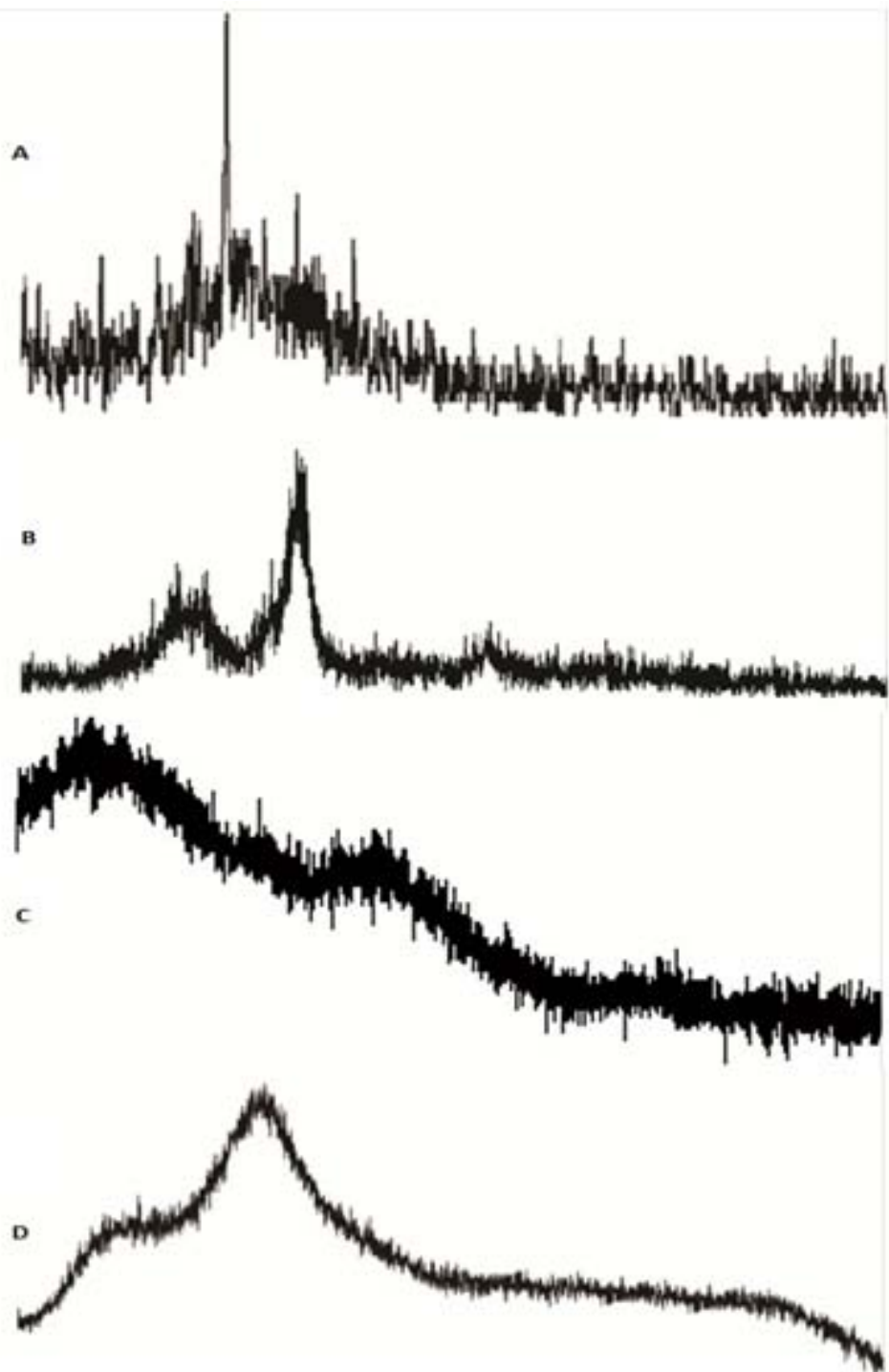

Fig. 11: X-ray diffraction patterns of A) TMX B) MCC C) PEG 6000 D) methyl cellulose and E) pellets

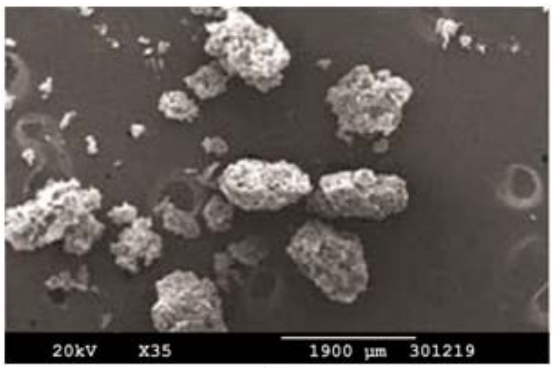

a
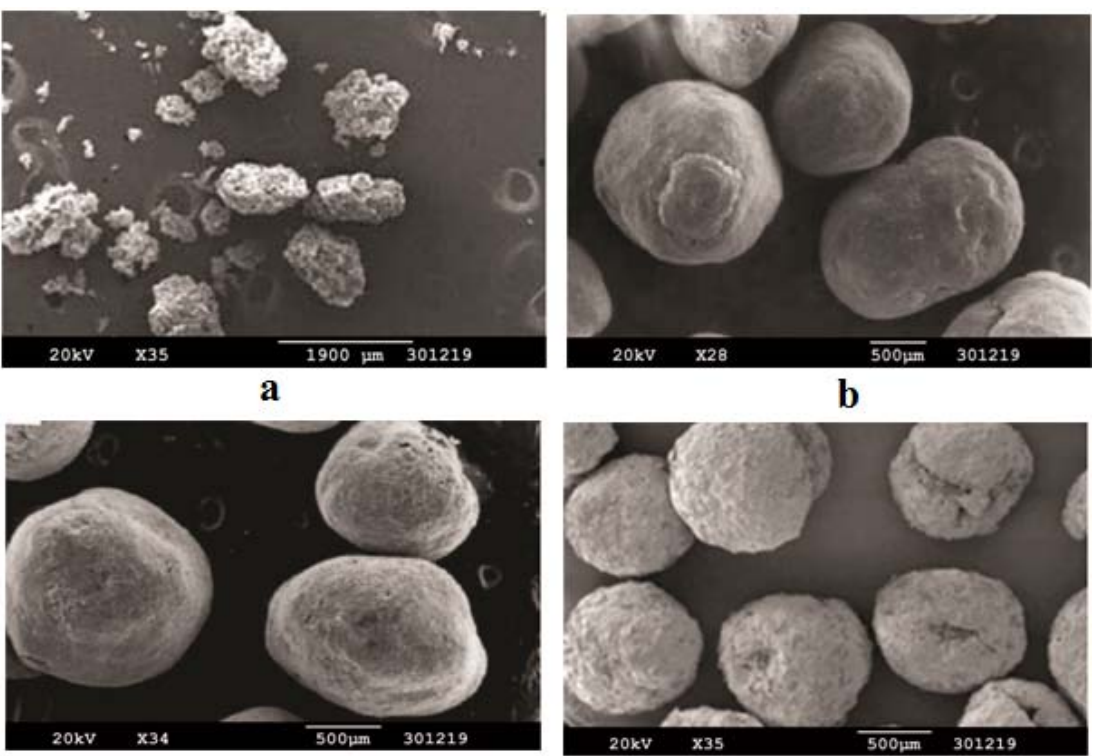

c

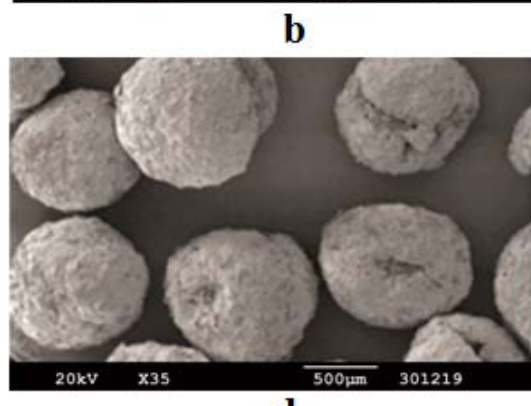

d

Fig. 12: SEM images of TMX (12a) and pellets (12b, $c$ and d) 


\section{Accelerated stability studies}

The optimized immediate release pellets were subjected to accelerated stability studies $\left(40{ }^{\circ} \mathrm{C} \pm 2{ }^{\circ} \mathrm{C} / 75 \% \mathrm{RH} \pm 5 \%\right)$ for $6 \mathrm{mo}$. Stability of immediate release pellets was also studied at room temperature for $6 \mathrm{M}$. The samples were withdrawn from both the stability conditions at $1 \mathrm{M}, 2 \mathrm{M}, 3 \mathrm{M}$ and $6 \mathrm{M}$. The samples were analyzed for their drug content and dissolution profile (table 5). The drug content of the immediate release pellets on stability ranged from $98.23-100.54 \%$. Almost constant drug content within
Pharmacopoeial limits $(95 \%-105 \% \mathrm{w} / \mathrm{w})$ indicates that immediate release pellets are stable till $6 \mathrm{M}$ at room temperature and at accelerated stability conditions. To asses change in release profile statistically, similarity factor (f2) was calculated. Similarity factor is a fit factor which is essentially a quantitative method, that reflects the differences between the two release curves. The f2 or similarity factor of immediate release pellets was found to be $>90$ for all the stability samples with respect to their initial release profile. This indicates that the release pattern of immediate release pellets is not affected by the stability conditions fig. 13 .

Table 5: Assay stability samples immediate release pellets at $1 \mathrm{M}, 2 \mathrm{M}, 3 \mathrm{M}$, and $6 \mathrm{M}$

\begin{tabular}{|c|c|c|c|c|c|}
\hline \multirow[t]{2}{*}{ Parameter } & \multirow[t]{2}{*}{ Duration } & \multicolumn{2}{|c|}{$40{ }^{\circ} \mathrm{C} \pm 2{ }^{\circ} \mathrm{C} / 75 \% \mathrm{RH} \pm 5 \%$} & \multicolumn{2}{|c|}{ At room temperature } \\
\hline & & HDPE & Alu. strip & HDPE & Alu. strip \\
\hline Assay & $1 \mathrm{mo}$ & $98.35 \pm 1.30$ & $99.57 \pm 1.85$ & $98.86 \pm 1.33$ & $99.74 \pm 1.86$ \\
\hline \multirow[t]{3}{*}{ (\%) } & $2 \mathrm{mo}$ & $99.25 \pm 1.25$ & $98.99 \pm 1.62$ & $99.65 \pm 1.41$ & $101.02 \pm 1.36$ \\
\hline & $3 \mathrm{mo}$ & $100.45 \pm 1.41$ & $100.26 \pm 1.23$ & $100.54 \pm 1.28$ & $99.47 \pm 1.42$ \\
\hline & $6 \mathrm{mo}$ & $98.23 \pm 1.45$ & $99.26 \pm 1.52$ & $99.62 \pm 1.22$ & $98.87 \pm 1.31$ \\
\hline
\end{tabular}

*All values represent mean \pm standard deviation $(\mathrm{n}=3)$

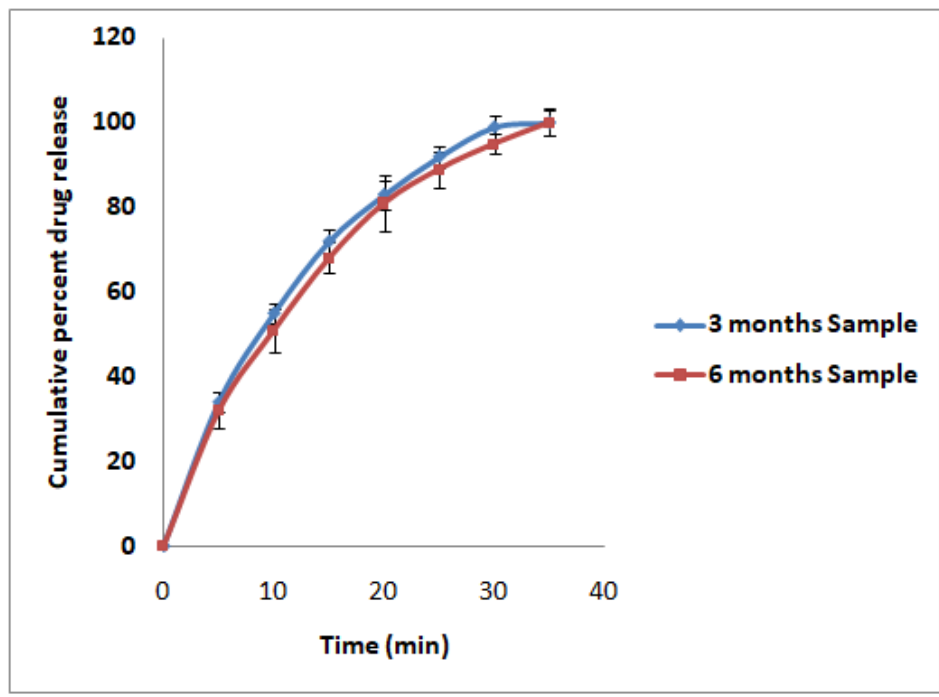

Fig. 13: Dissolution profile of initial, 3 Mo and 6 Mo stability sample of tamoxifen citrate immediate release pellets

\section{In vitro cell cytotoxicity and viability assay}

Reduced apoptosis was observed for optimized immediate release pellets on MCF-7 cells, which may be due to the fact that the antiapoptotic factor Bcl-2 (B Cell Lymphoma-2) was overexpressed and caspase- 3 is a major component of the effector phase of the majority of apoptotic signaling pathways, was not expressed. Therefore, the optimized immediate release pellets demonstrated less toxicity on MCF-7 cells [28].

Another observation made in case of MTT results of MCF-7 cells mentioning is that the optimized immediate release pellets show maximum cytotoxicity at $80 \mu \mathrm{g} / \mathrm{ml}$ on MCF-7 cell lines as can be observed from the (fig. 14, 15, 16).
The cytotoxicity at $80 \mu \mathrm{g} / \mathrm{ml}$ concentration was $37.13 \%$ for MCF-7 cells. This may be due to facilitated uptake of a drug at these concentrations, which results in more drug molecules to be available inside the cell, hence leading to increased cytotoxicity. MWCNTs-cell membrane interaction could also affect cellular response and cytotoxicity, the higher toxicity exhibited by optimized immediate release pellets at higher concentrations (viz. $100 \mu \mathrm{g} / \mathrm{ml}$ ) may be due to the aggregation of the drug at this concentration which could impair the plasma membrane, leading to cell death. This explains the reason for enhanced cytotoxicity of the optimized immediate release pellets at $80 \mu \mathrm{g} / \mathrm{ml}$ rather than at $100 \mu \mathrm{g} / \mathrm{ml}$ (table 6).

Table 6: \% Cell viability and \% cell cytotoxicity at different (1 to $100 \mu \mathrm{g} / \mathrm{ml}$ ) concentrations on MCF-7 cell lines

\begin{tabular}{lllllc}
\hline Group & O. D. & & & Mean \pm SD* & \% Viability \\
\hline Vehicle Control & 0.060 & 0.036 & 0.082 & $0.059 \pm 0.023$ & - \\
Control & 0.149 & 0.132 & 0.115 & $0.132 \pm 0.017$ & - \\
$1 \mu \mathrm{g} / \mathrm{ml}$ & 0.137 & 0.123 & 0.106 & $0.122 \pm 0.016$ & $92.42 \pm 1.21$ \\
$10 \mu \mathrm{g} / \mathrm{ml}$ & 0.105 & 0.127 & 0.111 & $0.114 \pm 0.011$ & $86.36 \pm 1.15$ \\
$20 \mu \mathrm{g} / \mathrm{ml}$ & 0.106 & 0.102 & 0.105 & $0.104 \pm 0.002$ & $78.78 \pm 1.51$ \\
$40 \mu \mathrm{g} / \mathrm{ml}$ & 0.099 & 0.092 & 0.095 & $0.095 \pm 0.006$ & $71.96 \pm 0.98$ \\
$80 \mu \mathrm{g} / \mathrm{ml}$ & 0.088 & 0.077 & 0.081 & $0.082 \pm 0.004$ & $62.87 \pm 1.32$ \\
$100 \mu \mathrm{g} / \mathrm{ml}$ & 0.096 & 0.088 & 0.092 & $0.092 \pm 0.006$ & $69.69 \pm 0.96$ \\
\hline
\end{tabular}

*All values represent mean \pm standard deviation $(n=3)$ 


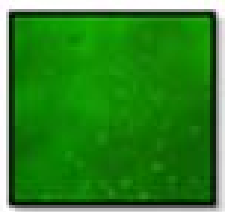

(A)

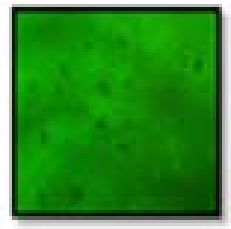

(D)

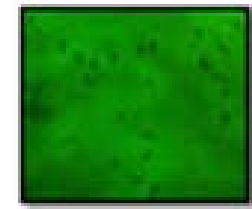

(G)

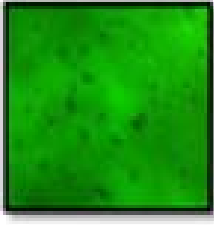

(E)

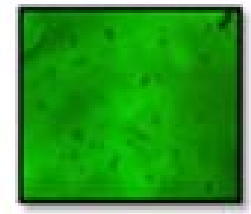

(H)
Fig. 14: Inverted Microscopic Images of MCF-7 Cells at 0 D (A) Control-1, (B) Control-2, (C) $1 \mu \mathrm{g} / \mathrm{ml}$, (D) $10 \mu \mathrm{g} / \mathrm{ml}$, (E) 20 $\mu \mathrm{g} / \mathrm{ml}$, (F) $40 \mu \mathrm{g} / \mathrm{ml}$, (G) $80 \mu \mathrm{g} / \mathrm{ml}$, (H) $100 \mu \mathrm{g} / \mathrm{ml}$

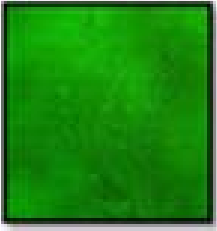

(A)

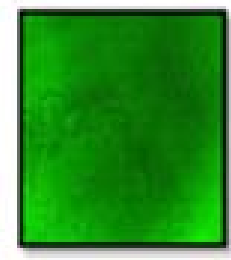

(D)

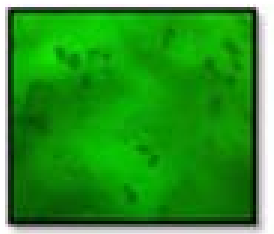

(G)

(E)

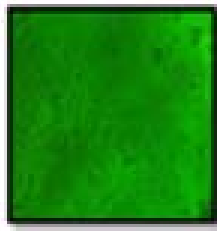

(B)
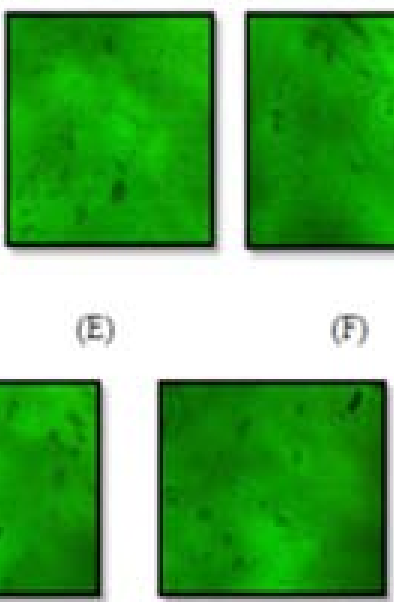

(H)
Fig. 15: Inverted Microscopic Images of MCF-7 Cells treated with optimised immediate release pellets after $24 \mathrm{~h}$. (A) Control-1,

(B) Control-2, (C) $1 \mu \mathrm{g} / \mathrm{ml}$, (D) $10 \mu \mathrm{g} / \mathrm{ml}$, (E) $20 \mu \mathrm{g} / \mathrm{ml}$, (F) 40 $\mu \mathrm{g} / \mathrm{ml},(\mathrm{G}) 80 \mu \mathrm{g} / \mathrm{ml},(\mathrm{H}) 100 \mu \mathrm{g} / \mathrm{ml}$

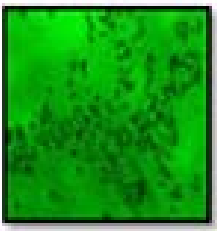

(A)

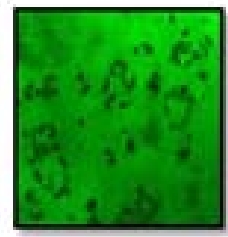

(D)

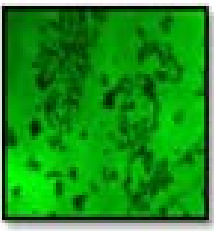

(B)

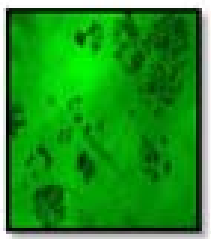

(E)

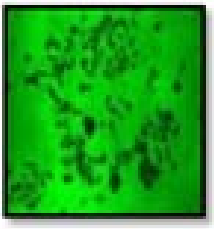

(C)

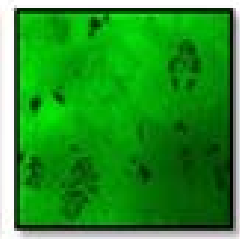

(F)

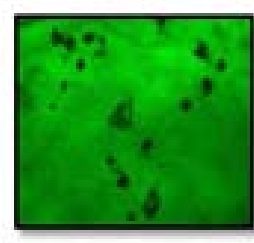

(G)

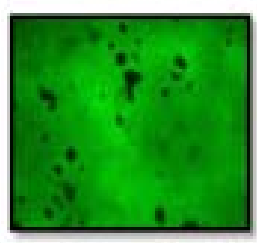

(H)
Fig. 16: Inverted Microscopic Images of MCF-7 Cells treated with after addition of MTT (A) Control-1, (B) Control-2, (C) $1 \mu \mathrm{g} / \mathrm{ml}$, (D) $10 \mu \mathrm{g} / \mathrm{ml}$, (E) $20 \mu \mathrm{g} / \mathrm{ml}$, (F) $40 \mu \mathrm{g} / \mathrm{ml}$, (G) $80 \mu \mathrm{g} / \mathrm{ml}$, (H) 100 $\mu \mathrm{g} / \mathrm{ml}$

\section{CONCLUSION}

The present study concluded that PEG 6000 and methylcellulose (MC) can effectively improve the dissolution behavior of tamoxifen citrate. The study also concluded that there is a positive effect of the amount of PEG 6000, Spheronization speed rate and negative effect of the amount of PEG Croscarmellose sodium on the dissolution efficiency. The results of the present study showed that hot-melt extrusion method and materials i.e. PEG 6000 and methylcellulose (MC) can constitute an excellent alternative to conventional polymers. The HME technique can be a proficient, environmental friendly and cost-effective tool for formulating pellets of immediate release drug delivery system.

\section{ACKNOWLEDGMENT}

Authors are thankful to USV Private Limited Govandi, Mumbai, India for providing gift sample of tamoxifen citrate. Authors are also thankful to Department of Pharmaceutics, School of Pharmaceutical Sciences, VISTAS, Pallavaram, Chennai for their motivation and support.

\section{AUTHORS CONTRIBUTIONS}

Both the authors contributed equally for performing this study and for writing manuscript.

\section{CONFLICT OF INTERESTS}

The authors declare that no conflict of interest

\section{REFERENCES}

1. Monteagudo E, Gandola Y, Gonzalez L, Bregni C, Carlucci AM. Development, characterization, and in vitro evaluation of tamoxifen microemulsions. J Drug Delivery 2012:1-11. http://dx.doi.org/10.1155/2012/236713

2. Wu CB, McGinity JW. Influence of methylparaben as a solid-state plasticizer on the physicochemical properties of Eudragit (R) RS PO hot-melt extrudates. Eur J Pharm Biopharm 2003;56:95-100. 
3. Reddy LH, Vivek K, Bakshi N, Murthy RSR. Tamoxifen citrate loaded solid lipid nanoparticles (SLN ${ }^{\mathrm{TM})}$ : preparation, characterization, in vitro drug release, and pharmacokinetic evaluation. J Pharm Dev Tech 2006;11:167-77.

4. Borgna JL, Rochefort H. High-affinity binding to the estrogen receptor of [3H] 4-hydroxy tamoxifen, an active antiestrogen metabolite. Mol Cell Endocrinol 1980;20:71-85.

5. Shin SC, Choi JS, Li X. Enhanced bioavailability of tamoxifen after oral administration of tamoxifen with quercetin in rats. Int J Pharm 2006;313:144-9.

6. Gao S, Singh J. In vitro percutaneous absorption enhancement of lipophilic drug tamoxifen by terpenes. J Controlled Release 1998;5:193-9.

7. Koo OMYK, Heng PWS. The influence of microcrystalline cellulose grade on shape and shape distributions of pellets produced by extrusion-spheronization. Chem Pharm Bull 2001;49:1383-7.

8. Howard MA, Neau SH, Marvin JS. PEO and MPEG in high drug load extruded and spheronized beads that are devoid of MCC. Int J Pharm 2006;307:66-76.

9. Rehana BA, Ganesh NS, Vineeth C. A study on different pellet formation techniques and its evaluation parameters-a review. Int J Curr Pharm Res 2019;11:7-13.

10. Podczeck F, Rahman SR, Newton JM. Evaluation of a standardized procedure to assess the shape of pellets using image analysis. Int J Pharm 1999;192:123-8.

11. Almeida Prieto S, Blanco Mendez J, Otero Espinar FJ. Microscopic image analysis techniques for the morophologicalcharterization of pharmaceutical particles: influence of the software and the factor algorithms used in the shape factor estimation. Eur J Pham Biopharm 2007;67:766-76.

12. Chopra R, Newton JM, Alderborn G, Podczeck F. Preparation of pellets of different shape and their characterization. Pharm Develop Technol 2001;6:495-503.

13. Steckel H, Mindermann Nogly F. Production of chitosan pellets by extrusion/spheronization. Eur J Pharm Biopharm 2004;57:105-14.

14. Tongwen X, Binglin H. Mechanism of sustained drug release in diffusion controlled polymer matrix application of percolation theory. Int J Pharma 1998;170:139-49.

15. Sousa A, Podczeck F, Newton JM. Factors influencing the physical characteristics of pellets obtained by extrusionspheronization. Int J Pharm 2002;232:91-106.

16. Newton JM, Pinto MR, Podczeck F. The preparation of pellets containing a surfactant or a mixture of mono-and di-glycerides by extrusion/spheronization. Eur J Pharm Sci 2007;30:333-42.
17. Ahuja N, Katare OP, Singh B. Studies on dissolution enhancement and mathematical modeling of drug release of poorly water-soluble drug using water-soluble carriers. Eur J Pharm Biopharm 2007;65:26-38.

18. Friedrich H, Nada A, Bodmeier R. Solid state and dissolution rate characterization of Co-ground mixtures of nifedipine and hydrophilic carriers. Drug Dev Ind Pharm 2005;31:719-28.

19. Sonaglio D, Beringhs AO, Porfírio A, Bataille B. On the factors influencing the extrusion strain, particle size and dissolution behavior of multiparticulate systems obtained by extrusion/spheronization. Powder Technol 2012;230:54-62.

20. Emara LH, Abdelfattah FM, Taha NF, El-Ashmawy AA, Mursi NM. In vitro evaluation of ibuprofen hot-melt extruded pellets employing different designs of the flow through cell. Int J Pharm Pharm Sci 2014;6:192-7.

21. Chamsai B, Sriamornsak P. Novel disintegrating microcrystalline cellulose pellets with improved drug dissolution performance. Powder Technol 2013;233:278-85.

22. Patadia J, Tripathi R, Joshi A. Melt-in-mouth multiparticulate system for the treatment of ADHD: a convenient platform for pediatric use. AAPS PharmSciTech 2016;17:878-90.

23. Kim MS, Jin SJ, Kim JS, Park HJ, Song H, Neubert RHH, et al. Preparation, characterization, and in vivo evaluation of amorphous atorvastatin calcium nanoparticles using supercritical antisolvent (SAS) technique. Eur J Pharm Biopharm 2008;69:454-65.

24. Maghraby GM, Alomrani AH. Synergistic enhancement of itraconazole dissolution by ternary system formulation with pluronic F68 and hydroxypropylmethylcellulose. Sci Pharm 2009;77:401-17.

25. Goddeeris C, Van den Mooter G. Free flowing solid dispersions of the anti-HIV UC 781 with poloxamer 407 and a maximum amount of TGPS 1000: investigating the relationship between physicochemical characteristics and dissolution behavior. Eur J Pharm Sci 2008;35:104-13.

26. Waseda Y, Matsubara E, Shinoda K. X-Ray diffraction crystallography introduction, examples and solved problems. Springer, Germany; 2011

27. Pradhan DK, Chaudhary RNP, Samantharay BK, Karan NK, Katiyar RS. Effect of plasticizer on structural and electrical properties of polymer nanocomposite electrolytes. Int J Electrochem Sci 2007;2:861-71.

28. Sharma S, Kumar V. In vitro cytotoxicity effect on mcf-7 cell line of co-encapsulated artesunate and curcumin liposome. Int J Pharm Pharm Sci 2017;9:123-8. 